\title{
Satellite Power System (SPS) Financial/Management Scenarios
}

October 1978

\section{U.S. Department of Energy}

Office of Energy Research

Satellite Power System Project Office

Washington, D.C. 20545

Under Contract No. EG-77-C-01-4024

\section{DOE/NASA}

SATELLITE POWER SYSTEM

Concept Development and

Evaluation Program 


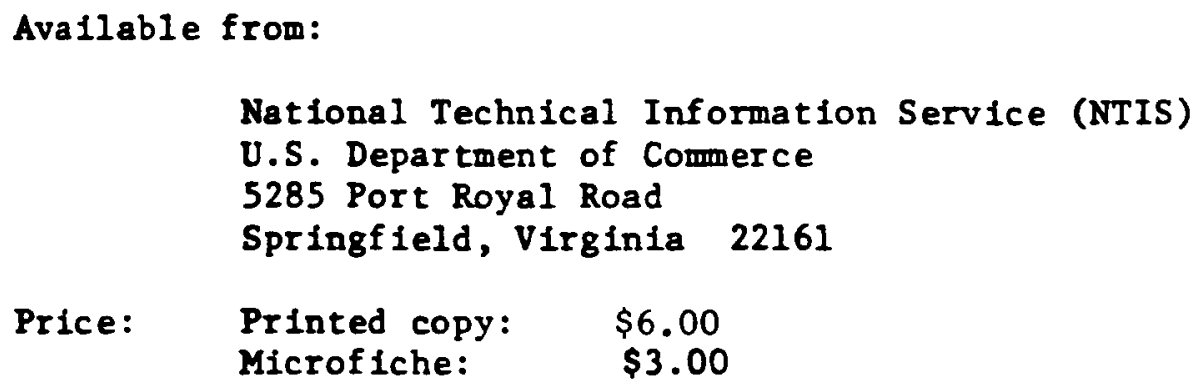




\section{Satellite Power System (SPS) Financial/Management Scenarios}

October 1978

Prepared by:

J. Peter Vajk, Principal Investigator

Science Applications, Inc.

Pleasanton, California

for the

PRC Energy Analysis Company

McLean, Virginia 22102

Prepared for:

U.S. Department of Energy

Office of Energy Research

Satellite Power System Project Office

Washington, D.C. 20545

Under Contract No. EG-77-C-01-4024

\section{DOE/NASA}

SATELLITE POWER SYSTEM

Concept Development and

Evaluation Program 


\section{NOTICE}

This report was prepared as an account of work sponsored by the United States Government. Neither the United States nor the United States Department of Energy, nor any of their employees, makes any warranty, express or implied, or essumes any legal liability or responsibility for the accuracy, completeness, or usefulness of any information, apparatus, product, or process disclosed, or represents that its use would not infringe privately owned rights. Reference herein to any specific commercial product, process, or service by trade name, mark, manufacturer, or otherwise, does not necessarily constitute or imply its endorsement, recommendation, or favoring by the United States Government or any agency thereof. The views and opinions of authors expressed herein do not necessarily state or reflect those of the United States Government or any agency thereof. 
The author acknowledges the following people for their review of the first draft of this White Paper:

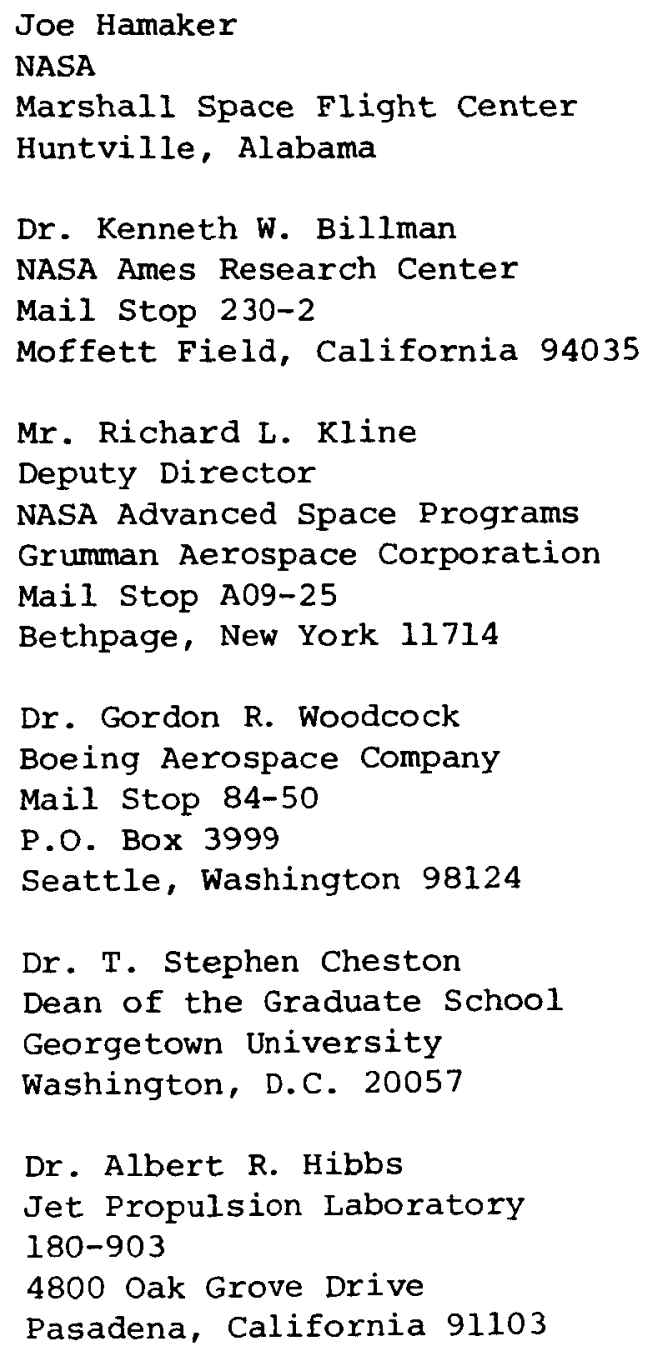




\section{EXECUTIVE SUMMARY}

Solar Power Satelites reve attrastes irneasir attention and interest in recent years as a possible lone-temi solution to the enerey needs of the United States and the world. At the present time, however, the estimated costs for research and development prior to derloyment of the first unit present a formidable challense to comercial implementation.

The capital cost per kilowatt for the WASA Reference Design (about $\$ 2500$ per kilowatt) is sufficiently higi to make this design marginally competitive, at best, with nuclear power in the 1990 's. Thus approaches to financing and managing an SPS program in which innovative designs could be developed and fostered must be sought out and given high consideration.

The problems of financing and managing a large-scale, lengthy SPS program reduce to the key questions of ownership and control. Ownership (that is, the sources of capital) may be govermmental, corporate, or individual; control may be exercised by a govermment agency, a government-sanctioned monopoly, or a competitive corporation.

Since the R\&D phase and the commercial implementation phase of an SPS program are qualitatively very different with respect to length of time before returm-on-investment, we have considered two general categories of SPS organizations: (1) organizations capable of carrying out a complete SPS program, from R\&D through commercialization; (2) organizations capable of carrying out commercial implementation only.

Six organizational models for carrying out the complete SPS program have been examined in some detail:

1. Existing government agencies (DOE, NASA, etc.)

2. A new government agency, "patterned after TVA.

3. A taxpayer stock corporation, a new concept.

4. A trust fund supported by energy taxes, pattermed after the financing of the Interstate Highway System.

5. A federal agency financed by bonds, pattermed after the Federal National Mortgage Association.

6. The staging company, a new concept, already in the early stages of implementation as a private venture.

Four additional organizational forms have been considered for commercial implementation of SPS:

7. A government-chartered monopoly, patterned after the Communications Satellite Corporation.

8. The consortium model, already widely used for largescale projects.

9. The corporate socialism model, patterned after such developements as the transcontinental railroad.

10. The universal capitalism model, a concept partially implemented in the 1976 legislation creating Employee Stock Ownership Plans.

A number of qualitative criteria for comparative assessment of these alternatives have been developed. Further work to define the advantages and liabilities of these altermatives is needed. The most probable implementation of an SPS program will involve a combination of the above methods. Models $3,5,6$, and 10 , in particular, require much more study since we have little or no historical basis for evaluating these models. 


\section{TABLE OF CONTENTS}

EXECUTIVE SUMMARY V v

I. INTRODUCTION 1

II . SURVEY OF RELEVANT LITERATURE 5

III. ANALYSIS AND EVALUATION

CAPITAL REQUIREMENTS FOR SPS 7

$\begin{array}{ll}\text { OWNERSHIP AND CONTROL } & 12\end{array}$

$\begin{array}{ll}\text { MANAGEMENT PRINCIPLES } & 17\end{array}$

ORGANIZATIONAL FORMS FOR SPS 18

CRITERIA FOR EVALUATION 21

DETAILED DESCRIPTIONS AND PRELIMINARY EVALUATION OF ALTERNATIVES 29

PHASED APPROACHES 53

COMPARATIVE EVALUATION 54

IV. KEY ISSUES AND OBSERVATIONS 56

V. RECOMMENDATIONS FOR FURTHER STUDY 59

$\begin{array}{lr}\text { REFERENCES } & 63\end{array}$

$\begin{array}{lr}\text { BIBLIOGRAPHY } & 65\end{array}$

$\begin{array}{lll}\text { APPENDIX I. MANAGEMENT PRINCIPLES } & 67\end{array}$

$\begin{array}{llll}\text { APPENDIX II. UNIVERSAL CAPITALISM } & 71\end{array}$ 


\section{INTRODUCTION}

The concept of harvesting renewable solar energy in space for transmission to Earth for terrestrial use has attracted increasing interest and attention in recent years. A number of design alternatives have been considered, including transmission of energy by microwave beam, by laser beam, or by reflection of raw sunlight; geosynchronous equatorial orbit, sun-synchronous orbits, or highly elliptical polar orbits; actively stabilized configurations or gravity-gradient stabilized configurations; photovoltaic conversion, thermionic conversion, or thermal cycle conversion; construction from terrestrial materials in low Earth orbit, construction from terrestrial materials in geosynchronous orbit, or construction from non-terrestrial materials in high Earth orbits, using either the Moon or Earth-crossing asteroids as the primary material source; and countless others.

Although these design variations imply large variations in Satellite Power System (SPS) program costs, it nonetheless appears to be the case that the initial investment costs for an SPS program based on any of the options discussed may total several tens of billions of dollars prior to the return of commercially significant quantities of power. The SPS concepts may prove to be economically superior to such alternatives as massive coal exploitation or widespread deployment of nuclear fission power reactors, but financing and managing a single integrated program of this scale poses problems of a kind which have never before been faced by the utilitles industry.

(Note that it is not the total cost of a thirty-year long program of construction which intimidates investors; rather it is the large costs before any power at all can be sold which presents the problem.)

The possible benefits of an SPS program, however, both domestically and internationally, justify detailed and imaginative investigation of the issues involved in financing and managing such a large-scale program. In this study, we have identified ten possible methods of financing an SPS program, ranging from pure government agency to private corporations. Most of these methods appear to have viable roles to play, at least in some phase of an SPS program.

We have briefly considered the cost estimates provided by $J$. Hamaker of NASA Marshal Space Flight Center for the SPS Reference Design ( 1 ). Originally, it had been our intention to perform a number of economic analyses of the flows of capital, interest, present value, discounted value, etc., for this program, 
but it soon became clear that such analyses would serve little purpose in evaluating the various schemes considered, except for noting two salient points:

(1) The SPS program naturally consists of two phases: a lengthy $R \& D$ phase in which as much as $\$ 45$ bilition must be expended to assure the economic and technical viability and credibility of the SPS program; and an Implementation phase, in which SPS's are constructed for use by commercial utilities or other large energy consumers.

(2) Capital cost per kilowatt of busbar capacity for the Reference Design is sufficiently high (more than $\$ 2500$ per kilowatt) to make the Reference Design marginaliy competitive, at best, with nuclear power in the 1990's, so that approaches in which innovative designs could be developed and fostered should receive high consideration.

\section{ASSUMPTIONS}

Our consideration of possible schemes for financing and managing an SPS program necessarily began with certain assumptions about economic and political factors. These assumptions were as follows:

1. Most of the actual work involved in the SPS program will be carried out by pre-existing contractors and subcontractors. During the Apollo program, more than 90\% of the funding passed through NASA to industrial and academic contractors who actually performed most of the R\&D, prototype construction and testing, and production or construction of hardware and equipment for ground facilities and for space missions.

Similarly, we assumed, the SPS organization will not enter the mining and refining business to produce aluminum and steel; it will not enter the manufacturing business to fabricate nuts and bolts and sheet stock; it will not enter the construction englneering business to build launch facilities or to prepare rectenna foundations. While an SPS organization may perform some in-house R\&D, most of that activity as well will be contracted out to industry and academia. The principal functions of an SPS organization, then, will be to provide overall technical guidance, program management and control, and financing for the project as a whole at each stage. 
2. We assume that the SPS program will be implemented only if the capital costs or the lifecycle costs of a power satellite are comparable to (or lower than) those of nuclear powerplants or of electrical generating plants burning fossil fuels (particularly coal). Should the SPS prove to be demonstrably cleaner from the viewpoint of environmental effects than the alternatives, or should an SPS program provide significant improvements in the U.S. balance of payments (through decreased requirements for petroleum imports), a modest premium in capital costs or lifecycle costs would perhaps be acceptable.

3. Assuming that capital costs and/or lifecycle costs for power satellites are competitive with alternative powerplants, we further assume that utility companies would be capable of financing the acquisition of power satellites in much the same manner as at present--by borrowing funds against future revenues from the sale of electric power.

(Some energy critics have suggested that the U.S. economy will not be able to support the capital requirements projected for electrical capacity growth during the next two or three decades. Whether or not this is true is irrelevant here--if the electric utilities can finance powerplants of any kind, they will be able to finance power sateliltes as well, provided Assumption 2 holds. If the utilities cannot afford conventional powerplants during this time period, SPS will have to become far less expensive than the Reference Design if an SPS program is to exist at alI.)

4. Although major shifts in public attitudes are to be expected over periods as long as the fifty years contemplated in this study, we have assumed that the "American system" will continue to be based primarily on private enterprise with varying degrees of governmental regulation. Public suspicion of very large corporations or of very large government agencies, we have also assumed, will continue, perhaps even increasing in strength. It is to be noted, however, that size in the public view is a relative matter. General Motors, for example, is probably perceived as "bigger" than Exxon, because of its large share of the automobile market, in contrast to the smaller share Exxon has of the petroleum industry, although Exxon's annual sales exceed those of General Motors. Large size is apparently less suspicious in the presence of vigorous competition (or, at least, the appearance of competition).

5. All cost and revenue figures quoted in this white paper are in constant dollars (1977-1978), without allowance for inflation. Thus interest rates and discount rates should be adjusted upward by the reader's estimate of inflation rates to obtain the equivalent rates in current dollars. (During most of this century, mortgage interest rates for private homes have approximated the expected long-term inflation rate plus $3 \%$. ) 
6. Cost estimates for the Reference Design are based on approximate relations developed from comparison of the more detailed Baseline Designs of NASA's Marshall Space Flight Center and NASA's Johnson Space Center. Ne1ther of these designs is a mature, fully-optimized system. Thus the cost estimates for the Reference SPS Design were considered exemplary only, and to the extent allowed by the level of effort avallable for this study, we considered some of the implications of significant reductions in these estimates. (Should costs prove to be substantially higher than the Reference Design, it seems most unlikely to us, in view of Assumptions 2 and 3 above, that such an SPS program would ever be implemented. Thus only cost reductions were of interest here.) In cases where the Reference Design specified a range of costs, we arbitrarily selected the corresponding costs from the Marshall Baseline Design if more concrete values were needed for purposes of analysis.

7. From the documentation available to us on the Reference Design, it was not entirely clear what was and what was not Included in the R\&D efforts. Accordingly, we have assumed that the costs quoted are for a completely self-contained SPS program which develops all space transportation systems and orbital facilities beyond the space shuttle system as well as the technology required for the power satellite itself, with no contributions from other space programs (such as advanced large-antenna communications and navigation systems, free-flying Spacelab, free-flying Shuttle power module, etc.). This assumption, it should be observed, places additional burdens on the viability of the SPS; should SPS prove viable despite these handicaps, it will in the real course of events be much more successful when integrated with such other activities.

8. The Reference Design assumes that two power satelities will be completed each year, each having a capacity of $5 \mathrm{GW}$. To simplify some of the financial analysis, it has occassionally been convenient to compute interest payments, revenues, and capitalization in annual increments. Thus for convenience we have frequently lumped two such $5 \mathrm{GW}$ power satellites together as a single $10 \mathrm{GW}$ system produced at the rate of one per year; the errors introduced by not including six months of interest on the costs of half of such a $10 \mathrm{GW}$ system are insignificant for our present purposes.

\section{ACKNOWLEDGEMENTS}

We are most grateful to Dr. Charles E. Bloomquist and to Mr. Alan P. Daurio of PRC Systems Service Company who provided a number of essential documents which would have been most difficult otherwise to obtain in a timely manner. We are also very grateful to $\mathrm{Mr}$. Wilfred Meliors of the European Space Agency in Washington who made a number of incisive and very helpful suggestions about the final report itself. 


\section{SURVEY OF RELEVANT LITERATURE}

Due to limitations on time and resources for this study, no attempt was made to perform a comprehensive literature survey. Due to the previous experience of the study team members in an 18-month study for NASA Marshall Space Flight Center on space Industrialization (1980 to 2010) (Ref. 2), we have a basic familiarity with the SPS literature. On this basis, we can state with some confidence that the bulk of the literature on the financing and management of a Satellite Power System program tends to be very general and qualitative, outlining general issues which must be addressed by any specific scheme. A substantial body of literature addresses such economic questions as cost/benefit ratios and discounted program costs, but these have little direct bearing on the problem at hand.

Three specific proposals have been advanced, however, outlining possible methods for financing and managing an SPS or an SPS/space colonization program, and these are examined here. The concept of using existing agencies (especially NASA and DOE) have also been suggested, but with little serious advocacy. A number of other historical precedents have occasionally been suggested in general terms as possible models for an SPS program, and these have also been considered here. Some of these alternatives would be more likely to succeed under certain economic reforms (especially with respect to tax laws), some of which have been advocated for reasons entirely independent of an SPS program. In these cases, the SPS program itself may provide an important incentive for implemetation of these reforms.

Some of the literature dealing with the general issues any specific SPS program must face is implicitly ideological, arguing that such a large and economically vital project as a large-scale energy system must (or must not) be entrusted to government rather than to private enterprise. Our own bias is in favor of private enterprise approaches for reasons we will discuss below.

A number of more general treatises on management in general and on management of large-scale undertakings have also been considered and their conclusions and recommendations will be reviewed below insofar as they appear to be specifically applicable to an SPS program.

The costs of an SPS program and of an individual power satellite are vitally important in the decision of whether or not to proceed with an SPS program. The literature on alternate design options is vast; the best studied alternatives are the MSFC and JSC Baseline Designs from which the Reference Design was derived. To the best of our knowledge, no other alternatives have been examined in nearly as much detail. Thus it is difficult. to know how far the capital cost per kilowatt of installed capacity might be reduced below the cost of the Reference Design. 
As an example of the potential alternative designs may have for reduction of costs, it appears on the basis of the 1977 NASA Ames Summer study on Space Manufacturing from Nonterrestrial Materials that the cost of a $10 \mathrm{GW}$ SPS could be $\$ 3.1$ billion (exclusive of ground station costs) versus approximately $\$ 18$ biliton for the Reference Design. The ground station costs quoted in the Reference Design amount to an additional $\$ 6.37$ billion; presumably this cost is independent of whether or not the space segment of the system uses terrestrial or non-terrestrial materials. This entire question of cost per unit, in our opinion, requires a great deal more study, considering the wide variety of design alternatives avallable and the impact of tile cost per unit on financial scenarios.

The sheer size of solar power satellites as presently envisioned ( 5 to $10 \mathrm{GW}$ each) poses significant problems for utility company system integration and financing. It should be noted, however, that the sizing of these designs is based on early system optimizations which traded off several engineering factors without consideration of the economic costs of integrating such large powerplants into networks consisting of much smaller units. The original trades included transmitter antenna size and mass, collector and converter system size and mass, space transportation costs, and average land costs. These factors were constrained by the assumption that the microwave flux density through the ionosphere would be limited by plasma instabilities to $23 \mathrm{~mW} / \mathrm{cm}^{2}$ or less. Furthermore, it was assumed that only geosynchronous orbit would be used, with a transmission frequency in the range of 2 to 5 Ghz.

Many of the costs assumed in these trades have changed during the last few years. It appears that significantly higher flux densities may be acceptable in the ionosphere; new technologies for the production of microwaves at far higher frequencies with high efficiency have been developed, allowing one to entertain the possibility of significant reductions in transmitter and receiver array areas; other orbits have become more attractive (at least politically); and the possibilities for construction of power satellites using nonterrestrial materials have become far more credible. New trades including some of these considerations as well as updated costs for factors included in the earlier trades should be done; if these trades suggest that 1 or $2 \mathrm{GW}$ sizes are feasible (or even optimal), the overall viability of an SPS program would be considerably enhanced, especially if front-end costs for the program scaled downward as well. 


\section{ANALYSIS AND EVALUATION}

\section{CAPITAL REQUIREMENTS FOR AN SPS PROGRAM}

The magnitude of the difficulties of financing and managing an SPS program are indicated by the cost estimates for the Reference Design as shown in Table I as provided by J. Hamaker of NASA Marshall Space Flight Center (1). The R\&D phase (which includes verification and design, development, test, and evaluation) is long and expensive. Procurement of parts, launch into space, and assembly in orbit of each $10 \mathrm{GW}$ increment of capacity, on the other hand, is expected to require only four years, with orbital assembly requiring only the last year of that period. The capital cost of about $\$ 2500$ per kilowatt is likely to be comparable to nuclear powerplants of equivalent capacity in the 1990's. (The Sundesert nuclear powerplant proposed for Southern California would have cost about $\$ 1700$ per kilowatt as of the late 1970's.)

As presented in the Reference Design, the commercialization phase is fairly slow in pace, bringing only $10 \mathrm{GW}$ of additional capacity on line each year. The rate of construction, however, could be three or four times higher, but the start-up costs would be somewhat higher due to the need for a larger fleet of launch and orbital transport vehicles and for more extensive orbital assembly and living facilities.

The very size of the project poses difficulties in financing and managing the program. Important issues of controlling a large array of people and contracting companies arise at once. Finding large sums of investment capital could be a problem, resulting in abrormally high interest costs. The risks to society inherent in such large concentrations of power--financial, social, and political --are not trivial.

In many respects, the question of how to manage such a program is secondary to the question of how to finance it. The principal differences in management between the various possible schemes we have considered appear to concern the interfaces the SPS organization will have to deal with in the implementation of the program. This problem, however, is merely a subset of the larger problem which every large-scale project must deal with if it is as large and as long as the SPS program is likely to be. That larger problem is to maintain close contact with the total human environment in which the project must operate. Should an SPS program be governmentally funded, it may have to deal with certain additional constraints applicable to virtually all government agencies in the United States, including the liabilities of the Civil Service system and the vicissitudes of Congressional and Executive support or opposition. 
TABLE I-A.

R\&D AND START-UP COSTS FOR SPS REFERENCE DESIGN (All figures in billions of 1978 dollars, with no inflation.)

\begin{tabular}{|c|c|c|c|c|c|}
\hline Year & $\begin{array}{l}\text { R\&D } \\
\text { cost }\end{array}$ & $\begin{array}{l}\text { Present } \\
\text { value } \\
\text { (1) }\end{array}$ & $\begin{array}{l}\text { Compounded } \\
\text { value } \\
(2)\end{array}$ & $\begin{array}{c}\text { Construction } \\
\text { start-up } \\
\text { cost }\end{array}$ & $\begin{array}{l}\text { Compounded } \\
\text { value } \\
\text { (2) }\end{array}$ \\
\hline $\begin{array}{l}1 \\
2 \\
3 \\
4 \\
5 \\
6 \\
7 \\
8 \\
9 \\
10 \\
11 \\
12 \\
13 \\
14 \\
15 \\
16 \\
17 \\
18\end{array}$ & $\begin{array}{r}0.19257 \\
0.54635 \\
0.80605 \\
0.93002 \\
0.90601 \\
0.74872 \\
1.99202 \\
4.46445 \\
6.28576 \\
7.20571 \\
7.01965 \\
5.80182 \\
3.87294 \\
1.78839 \\
0.30756 \\
-- \\
-- \\
\text { TOTAIS } 42.86804\end{array}$ & $\begin{array}{c}0.18136 \\
0.48457 \\
0.67327 \\
0.73158 \\
0.67119 \\
0.52236 \\
1.30885 \\
2.76253 \\
3.66302 \\
3.95458 \\
3.82812 \\
2.82405 \\
1.77538 \\
0.77207 \\
0.12504 \\
-- \\
-- \\
24.27797\end{array}$ & $\begin{array}{l}0.19695 \\
0.57096 \\
0.87188 \\
1.05258 \\
1.09311 \\
0.99984 \\
2.33326 \\
5.00623 \\
7.17855 \\
8.56333 \\
8.90256 \\
8.20752 \\
6.74228 \\
5.02721 \\
3.82355 \\
3.74543 \\
3.97703 \\
68.29227\end{array}$ & $\begin{array}{r}5.05000 \\
5.05000 \\
5.05000 \\
5.05000 \\
20.20000\end{array}$ & $\begin{array}{r}5.16491 \\
5.48429 \\
5.82342 \\
6.18352 \\
22.65615\end{array}$ \\
\hline
\end{tabular}

* Year 18 is the first full year of revenues from sale of electric power or from sale of completed power satelittes.

(1) The "present value" is the capital sum which would have to have been invested at the beginning of year 1 , earning $6 \%$ real interest continually compounded, to pay the expenses of the current year.

(2) The "compounded value" Is the sum of interest on all previous years' costs, interest on the current year's costs assumed to be paid out quarterly, and the current year's costs themselves. (A real interest, rate of $6 \%$ per year, compounded continually, has been assumed.) 
TABLE I-B.

CONSTRUCTION COSTS, OPERATIONS AND MAINTENANCE COSTS,

AND REVENUES FOR $10 \mathrm{GW}$ SPS CAPACITY

(All figures in billions of 1978 dollars, with no inflation.)

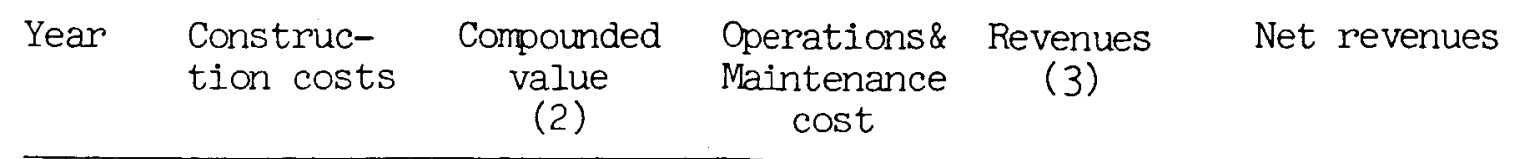

\begin{tabular}{|c|c|c|c|c|c|}
\hline & & & & & \\
\hline 14 & 6.03405 & 6.17136 & & & \\
\hline 15 & 6.03405 & 6.57657 & & & \\
\hline 16 & 6.03405 & 6.98324 & & & \\
\hline 17 & 6.03405 & 7.41506 & & & \\
\hline 18 & 24.13620 & 27.52784 & 0.32800 & 3.50400 & 3.17600 \\
\hline 19 & & & 0.32800 & 3.50400 & 3.17600 \\
\hline 20 & & & 0.32800 & 3.50400 & 3.17600 \\
\hline 21 & & & - & - & - \\
\hline 22 & & & - & . & . \\
\hline 23 & & & . & . & . \\
\hline 24 & & & $\cdot$ & • & $\cdot$ \\
\hline 25 & & & • & • & • \\
\hline 26 & & & $\cdot$ & - & - \\
\hline 27 & & & - & $\cdot$ & - \\
\hline$\cdot$ & & & - & - & - \\
\hline$\cdot$ & & & - & - & - \\
\hline$\cdot$ & & & $\cdot$ & - & • \\
\hline
\end{tabular}

(3) These revenues are computed on the basis of $10 \mathrm{GW}$ of power sold at $\$ 0.04$ per kilowatt-hour with $100 \%$ load factor.

(See Table I-A for other notes.) 
Table I-A shows the R\&D cash flow over the first fifteen years of the SPS program. For each year, the R\&D costs themselves are shown as well as the "present value" and the "compounded value" of that year's program. The "present value" is computed in the following way: suppose the R\&D expenditures of the $n$-th year were to be paid for out of an endowment fund deposited at interest at the beginning of the first year. How large an endowment would be required if the funds earned $6 \%$ real interest annually (after inflation) compounded continually?

The "compounded value" is computed on the converse assumptior. that each year's R\&D expenditures are paid for by borrowing money, again at $6 \%$ true interest per year, with interest on the previous-y accumulated debt accruing each year.

The direct costs for the R\&D program total $\$ 42.87$ billion. This could be provided by an initial endowment of $\$ 24.28$ billion invested as described above. If obtained by borrowing, the total indebtedness of the SPS program just before revenues begin from the first completed power satelite would be some $\$ 68.29$ billion. The high ratio of the compounded costs to the direct costs is the inevitable result of the prolonged nature of the R\&D phase. The high interest costs make the R\&D phase very difficult--if not impossible--for private industry to finance.

The total magnitude of the investment in the R\&D phase also appears intimidating, primarily because it is concentrated in a single venture. Even large private enterprise projects (such as the Alaska pipeline--total cost of about $\$ 7$ biliion) are far smalier, and certainly much shorter in duration, permitting recovery of investment within 5 to 8 years (typically).

We have assumed that the difference between the costs quoted for the "First Unit" and the costs quoted for the "Average Unit" in the SPS Reference Design are entirely attributable to construcjion start-up costs, including factories for the manufacture of SPS components, procurement of the fleet of launch vehicles and the fleet of orbital transport vehicles, preparation of launch and recovery facilities, and deployment of facilities in orbit for worker habitats and assembly equipment. These start-up costs total \$20.2 billion over a four year period just before revenues from sales of power satellites or from sales of electricity begin to come in. The ratio of the compounded value to the direct costs for the start-up phase is low, within a range acceptable to normai financing methods for private industry. The magnitude of the start-up costs may seem large, but even airline companies (far smaller in total assets than the utility companies) have placed orders for $\$ 2$ billion or more for new aircraft within the past year. These costs are expected to be amortized in less than ten years after delivery of the aircraft. 
The construction start-up costs could be amortized (including $6 \%$ real interest per annum) by annual charges of $\$ 4.06$ billion for 7 years; $\$ 3.08$ billion for ten years; or $\$ 1.98$ billion for twenty years, these charges to be included in the costs of SPS construction. It was unclear to us whether the "transportation" and "assembly" costs quoted in the Reference Design included amortization of this equipment or not; if not, the cost per unit would be higher during the first few years until the construction equipment and fleet are paid off, with a subsequent reduction in SPS cost.

Table I-B indicates the costs for construction and for operation and maintenance of a $10 \mathrm{GW}$ installation of power satellites as well as the revenues attributable to sales of electricity. (These revenues assume 100\% load factor and $40 \mathrm{mills}$ per kilowatt-hour.) Assuming 6\% real interest per annum to be the cost of money to a utility company, acquisition of a power satellite costing $\$ 24.14$ billion per $10 \mathrm{GW}$ could be paid off in approximately $10 \frac{1}{2}$ years out of the net revenues indicated, $\$ 3.176$ billion per year after operations and maintenance costs. Such a time scale is longer than typical industrial investments, but is not unreasonable for utility companies. (Should power satellites in the early commercialization phase have to assume the burden of amortizing the construction equipment at a fast pace, i.e.,\$4.06 billion per year additional, the payoff period for the first seven set $s$ of $10 \mathrm{GW}$ SPS installations would be about $13 \frac{1}{2}$ years.)

(If the Reference Design costs include amortization of the construction equipment and fleet, the payoff period for a utility company buying a power satellite would be just 7 years if the capital costs could be reduced from $\$ 24.14$ billion to $\$ 17.73$ billion, a price just a few percent higher per unit of capacity than the abandoned Sundesert nuclear powerplant.)

From the foregoing discussion, it should now be clear what is unique about the SPS program from a financing point of view: the magnitude and duration of the R\&D phase are much greater than anything the energy industry has hitherto attempted. Financing the acquisition of a power satellite is feasible for utility companies by conventional methods, provided capital and lifecycle costs per kilowatt of generating capacity are competitive with alternatives. Financing of the construction start-up costs is likewise possible by private industries willing to enter a new business. But the R\&D effort seems singularly difficult; no private investor would be willing to put up money for fifteen years or more before collecting dividends. The basic issue in financing an SPS program is the question of "filling up the hole," paying off the enormous negative cash flow incurred by the R\&D effort. Most of the existing literature on SPS assumes that only federal financing out of general tax revenues is capable of supplying the necessary funds. As we shall see, however, several alternatives car be devised, including one purely private enterprise approach presently in the early stages of actual implementation. 


\section{OWNERSHIP AND CONTROL}

The financing and the management of an enterprise represent, in effect, the two questions of ownership and of control. Whoever provides the capital for an enterprise is de jure the owner; depending on a number of institutional and legal considerations, however, the owners of the enterprise may have control over the day-to-day business decisions of the enterprise which range from absolute (as in sole proprietorship) to virtually non-existent (as in the case of an individual who owns a single share of a large multinational corporation such as Exxon or General Motors).

The ultimate source of capital for purposes of this discussion can be taken to be the individual. Figure 1 shows a variety of paths by which capital can flow from a individual to such a large-scale undertaking as an SPS program. The paths marked 1 and 3 in the figure are subject to the individual's control; the individual can allocate portions of his disposable income among various of these alternatives in accordance with his perception of the relative risks, returns, and desirabilities of these investment or savings opportunities. Only path 3 represents a direct investment in the SPS program, presumably by way of the stock market. Paths 1 represent indirect investments: the individual selects a decision-maker (such as the board of directors of a corporation, the investment managers of mutual fund, or the directors of a bank or savings and loan institution) and entrusts his funds to their care.

While the individual has a great deal of control over paths 1 and 3 , he has very little control over path 4 since the government sets the tax rates. The taxpayer's control is solely through electing officials and by lobbying, both of which take effect very slowly.

A potential SPS enterprise, then, must look to paths 2, 3 , or 5 for its sources of capital. Individuals and corporations are relatively free to determine whether or not to invest in an SPS enterprise on the basis of their own investment needs and guidelines, which seldom include cost/benefit analysis. More frequently, these decisions are based on subjective perceptions of risk, effective yield of the investment, potential for appreclation of value, or glamor of the investment. The government, on the other hand, must base its decision to invest on political considerations, including public support for a possible program, vociferous opposition for whatever reason, lobbying interests, regional tradeoffs, and economic analysis 


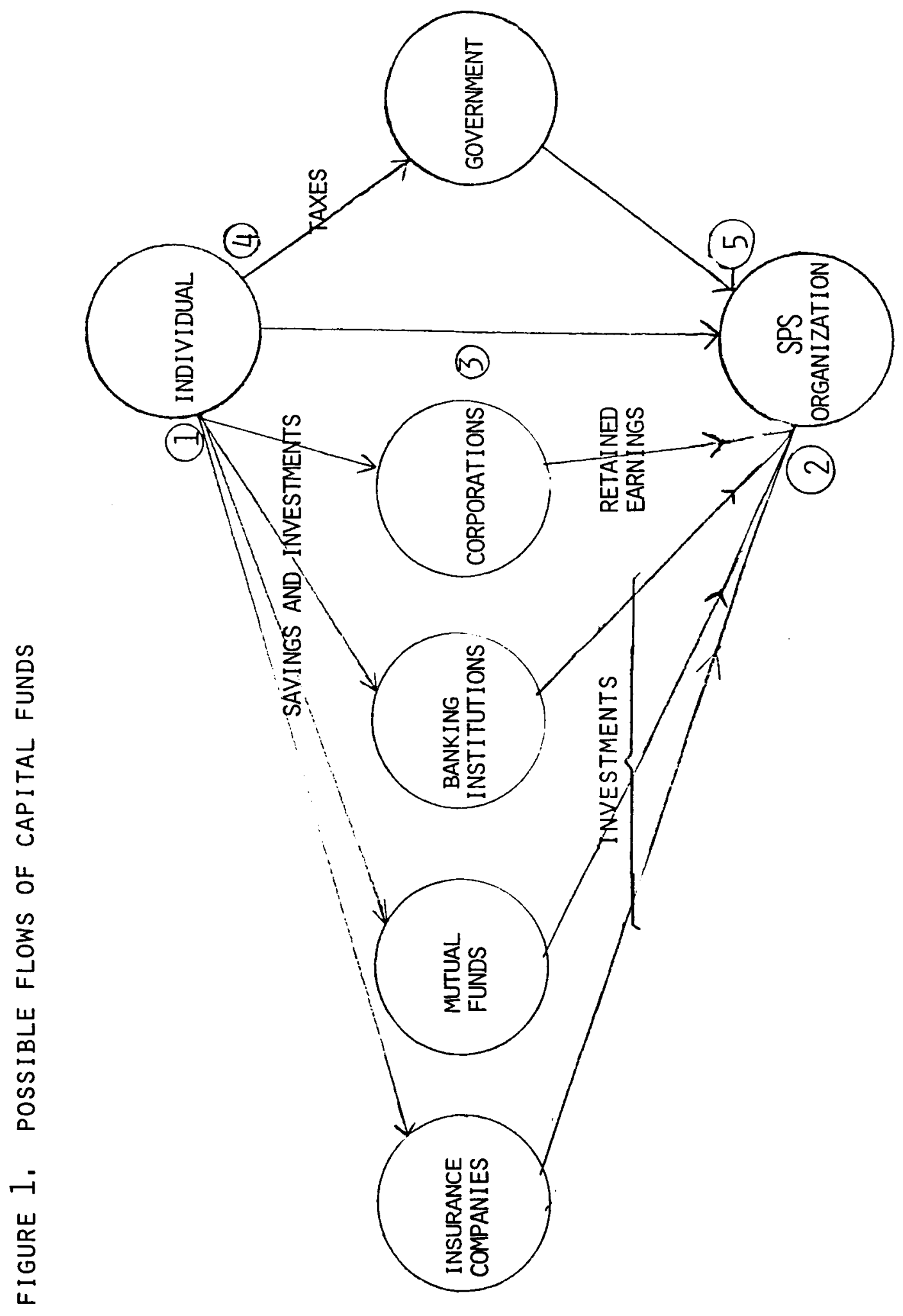


including cost/benefit considerations. Yield on investment and potential for appreciation seldom enter into consideration, although analyses of these types are sometimes used to justify or rationalize decisions made for other reasons.

Capital sources can thus be categorized into three basic channels: individual investments by the purchase of shares; corporate investments by insurance companies, mutual funds, banking institutions, or other business corporations; or government funding.

Once the individual has made his investment or paid his taxes, however, day-to-day control of the decisions of an SPS organization are quite beyond his reach, unless he owns a very large block of shares in the SPS organization. Large stockholders have absolute, undisputed control of a block of shares and can thus exert significant influence over the management of a corporation. A coalition of shareholders holding an equal number of shares is in fact weaker than that of a single stockholder since the diversity of personal interests and desires among them make it more difficult to achieve and sustain the concensus necessary for them to act forcefully and in unison.

The managers of an enterprise are subject to varying degrees of governmental control in their day-to-day decisions. Ultimatel:, the government has complete control of all enterprises in its jurisdiction since it defines the laws of the land, especially the tax laws, which can greatly affect the attractiveness of an investment. In practice, however, the government delegates varying amounts of control or freedom to different types of entities. It is convenient for these purposes to group possible SPS organizations into three basic types, in order of decreasing governmental control: Government agencies, government-sanctioned monopolies, and private, competitive corporations.

In the international context, organizational forms become somewhat less clear and easy to define, particularly since no single world government has jurisdiction over international economic activities. Existing multinational firms operate branches or subsidiaries in each country under its local laws and regulations, with greatly multiplied legal problems. The present day legal context is described concisely by Professor 


\section{Richard Falk (3) as follows:}

The basic coordinates of the present world order system are contained in the Peace of Westphalia which brought the Thirty Years War to an end in 1648. According to Westphalia logic, the world order system is constituted exclusively by the govermments of sovereign states. These governments have complete discretion to rule national space (or territory), and can also enter into voluntary arrangements (e.g., treaties) to regulate external relations and interconnections of various scrts. But these governments are sovereign and equal by juridical fiat, rather than by virtue of some higher authority within the world order system. No one government is entitled to greater formal status than another by reasons of wealth or power or size. In such circumstances, "law and order" rests upon the volition of goszermments and upon their perception of common interests.

Existing international enterprises of various sorts (other than multinational, private corporations) are based on treaty arrangements, bilateral or multinational accords and protocols, or subdivisions or subagencies of larger international entities such as the United Nations and the Organization for Economic Cooperation and Development. During the present century, one other type of entity was granted international legal recognition, namely, the free city of Danzig, but its existence was terminated by World War II. At least one proposal(4) has been made for the establishment of a space colonization/Solar Power Satelite enterprise under similar status which could be granted by the United Nations but the endorsement of the idea by dozens of nations would be required.

It thus appears that control of an internationally implemented SPS program would be most likely to involve either a government agency (such as the European Space Agency - 10 nations) or a government-sanctioned quasi-monopoly (such as INTELSAT - 102 nations.*) Several of these existing organizations which provide space-based telecommunications services are shown in Figure 2 , indicating their positions in the matric of capital sources versus

* INTELSAT is not, properly speaking, a monopoly, since the international agreements under which it was created cannot prevent other nations from forming their own analogous arrangements; this has in fact happened with the creation of INTERSPUTNIK ( 9 nations), ASTO (20 nations), and NTSC (5 nations). Within each of these groups, however, the organization enjoys monopoly itatus. 


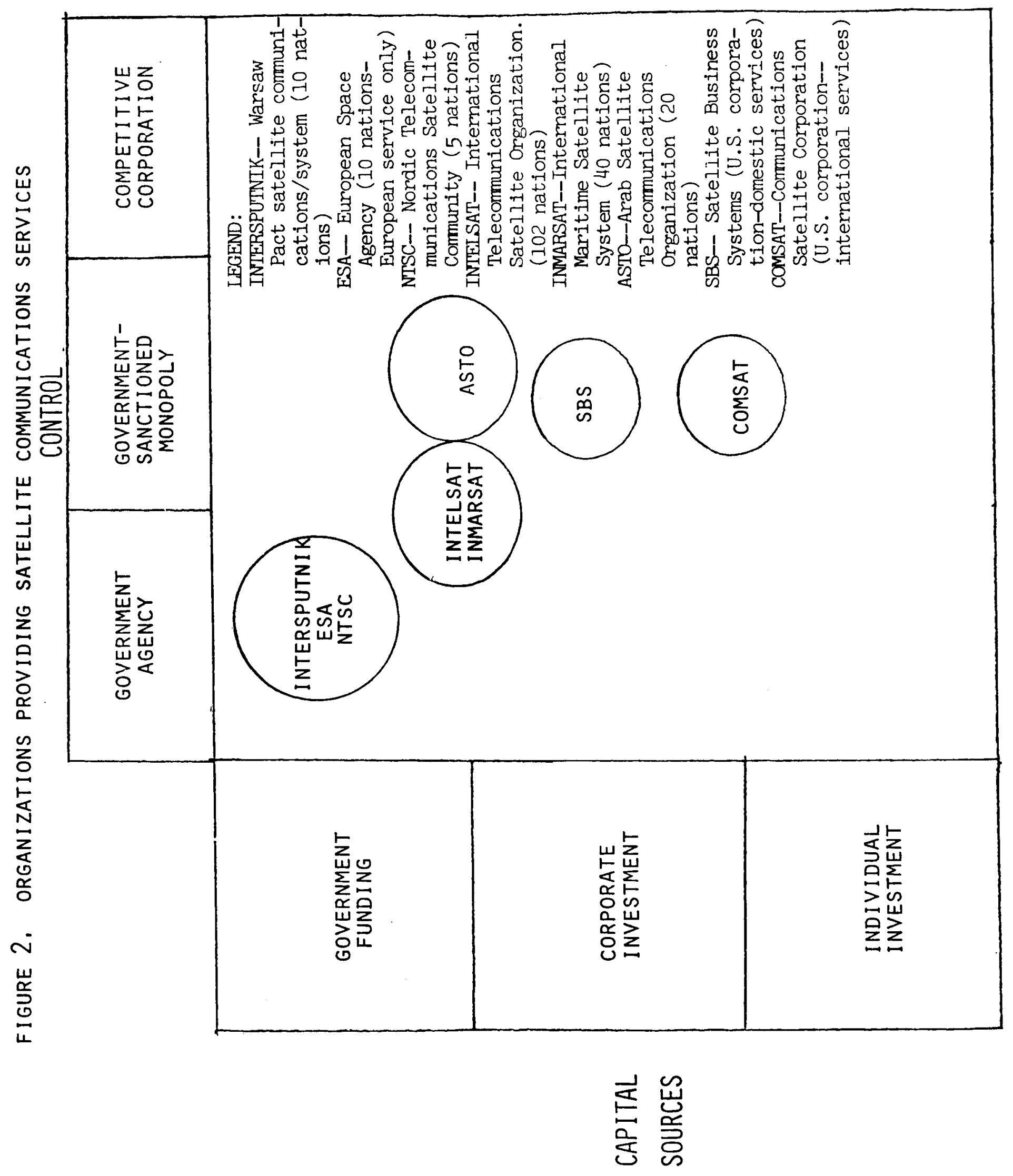


degree of governmental control. INMARSAT is still under negotiation prior to actual formation; COMSAT and SBS are domestic U.S. corporations which have been granted monopoly status as regulatec utilities. ESA provides communications within its member nations and thus does not compete directly with INTELSAT to which many ESA members also belong.

\section{MANAGEMENT PRINCIPLES}

From the viewpoint of management theory and practice, the SPS program poses difficulties on two fronts: first, the length of the program (especially the R\&D phase); and second, the scale of the undertaking in terms of annual cash flow and numbers of highly trained personnel working on a single project. But these are matters of degree rather than of kind, it seems to us, and a number of successful examples can be studied in recent history. These include the Apollo program, the Marshall Plan, and day-to-day management of organizations as large as General Motors or Exxon.

Regardless of the scale or duration of a project, performance of any task sufficiently complex to require the participation of more than a handful of people involves four key processes of management:

1. delegation of authority;

2. delegation of responsibility;

3. control; and

4. rewards and penalties.

For large-scale enterprises, especially those taking more than a few years until fruitful completion, several additional factors appear to be necessary for success; these have been discussed thoroughly in Reference (5) by James E. Webb:

1. organizational flexibility;

2. close interaction with the environment of the enterprise;

3. exceptional personnel;

4. fostering and using innovative ideas; and

5. avoidance of managerio-sclerosis.

These general principles will apply to any of the candidate SPS organization forms discussed below. Depending on the details of the financing of the SPS program, however, some differences may be necessary in the ways in which the SPS organizations interiace with suppliers, customers, investors, regulatory organizations, End other government agencies, both in the U.S. and abroad.

A more extensive discussion of the general principles listec above is given in Appendix I. 


\section{ORGANIZATIONAL FORMS FOR AN SPS PROGRAM}

Any proposed scheme for actual implementation of an SPS program must come to grips with the fact that a substantial investment of money and time must be made in R\&D (research and development: technology and system verification, and engineering design, development, testing, and evaluation) before the first commercial power satellite is built. The NASA Reference Design (in the Marshall Space Flight Center version) assumes a nine year verification program and a nine year DDT\&E program, with a three year overlap. The $R \& D$ program assumed here includes the development of advanced transportation systems and of orbital assembly and habitation facilities, as well as the development of SPS technology.

Actual construction of the first $5 \mathrm{GW}$ unit would begin in the 14 th year, overlapping the last two years of the DDT\&E effort. The fisrt unit would commence commercial operation at the end of the 17th year. The verification program is estimated to cost $\$ 4.9$ billion (uninflated 1978 doliars); the pre-construction DDT\&E program, another $\$ 35.88$ billion; and the final two years of DDT\&E (overlapping construction of the first unit), another $\$ 2.09$ billion.

While it may be possible to reduce the time scale from 13 years before initial construction to perhaps 8 or 10 years, and to reduce the costs by a factor of perhaps two, the front-end burden would still be a major impediment to conventional business investment approaches. As a general rule of thumb, industry cannot invest in capital equipment which will not pay for itself within flve to eight years; for utility companies, a new generating plant can take up to ten or twelve years to pay for itself, but the return on investment for the bondholders and stockholders is correspondingly lower for utility companies than for manufacturing companies, for example.

Once the technology for deployment of a commercial SPS has been developed, however, actual construction could be financed more or less conventionally, since revenues would commence as little as four years later, within the time frame feasible for private enterprise.

For these reasons, the qualitative differences between the $R \& D$ phase and the commercial implementation phase are enormous. Organizational designs for an SPS program must recognize these differences and come to grips with them. Failure to recognize these differences has lead many to assume (often tacitly) that only government ownership of the SPS enterprise is feasible. This need not be the case, however, if the SPS program is organized differently in the two successive phases. 
Accordingly, we have considered possible organizational forms for an SPS program in two major categories: (1) those organizational forms which could undertake the entire sPS program, from verification through DDT\&E into commercial implementation; and (2) those organizational forms which could undertake only the commercialization phase of the program, after technical and economic risks had been demonstrated to be acceptable by some other organization. A total of ten organizational models were considered in this study; their positions in the ownership/control matrix are shown in Figures 3, 4-A, and 4-B.

Possible organizational forms for carrying out the entire SPS program, from R\&D through commercialization, are shown in Figure 3. These candidate forms are as follows:

1. Existing government agencies (DOE, NASA, etc.)

2. New government agency, here designated the "Space Utilization Authority" as proposed by Philomena G. Grodzka ( 6 ) as an analog to the Tennessee Valley Authority .

3. Taxpayer stock corporation, herein designated "U.S. Powersat Service" due to some analogies to the U.S. Postal Service. This concept was first proposed by George E. Fredericks and Richard D. Stutzke ( 7 ) as a government chartered monopoly, although it could also be established as one of several competitive corporations.

4. Trust fund supported by energy taxes, here designated as "Federal Spacepower Trust Fund," an analog to the Federal Highway Trust Fund which created the Interstate Highway System with funds derived from gasoline taxes paid by all highway users in the United States.

5. Federal agency supported by floating long-term bonds backed by the Treasury, here designated "Federal National Space Projects Association" (nicknamed "Fannie Spray"), in close analogy to the Federal National Mortgage Association ("Fannie Mae").

6. The staging company concept, already incorporated in Delaware as of August 3, 1978, under the name International Satellite Industries, Inc., by attorney Christian 0. Basler of New York who first proposed this concept. ( 8 )

Several combinations of ownership and control are marked " $X$ " in Figure 3 to indicate that they are unlikely to be feasible combinations. Individual investment capital alone is almost certain to be insufficient to finance the entire duration of an SPS program, regardless of the degree of government control exercised over the project. Similarly, purely corporate investments in such a very long term project are virtually impossible except perhaps in very token amounts if they can be treated as philanthro: $-c$ tax deductions. The schemes shown in this diagram will be described in greater detail below. 


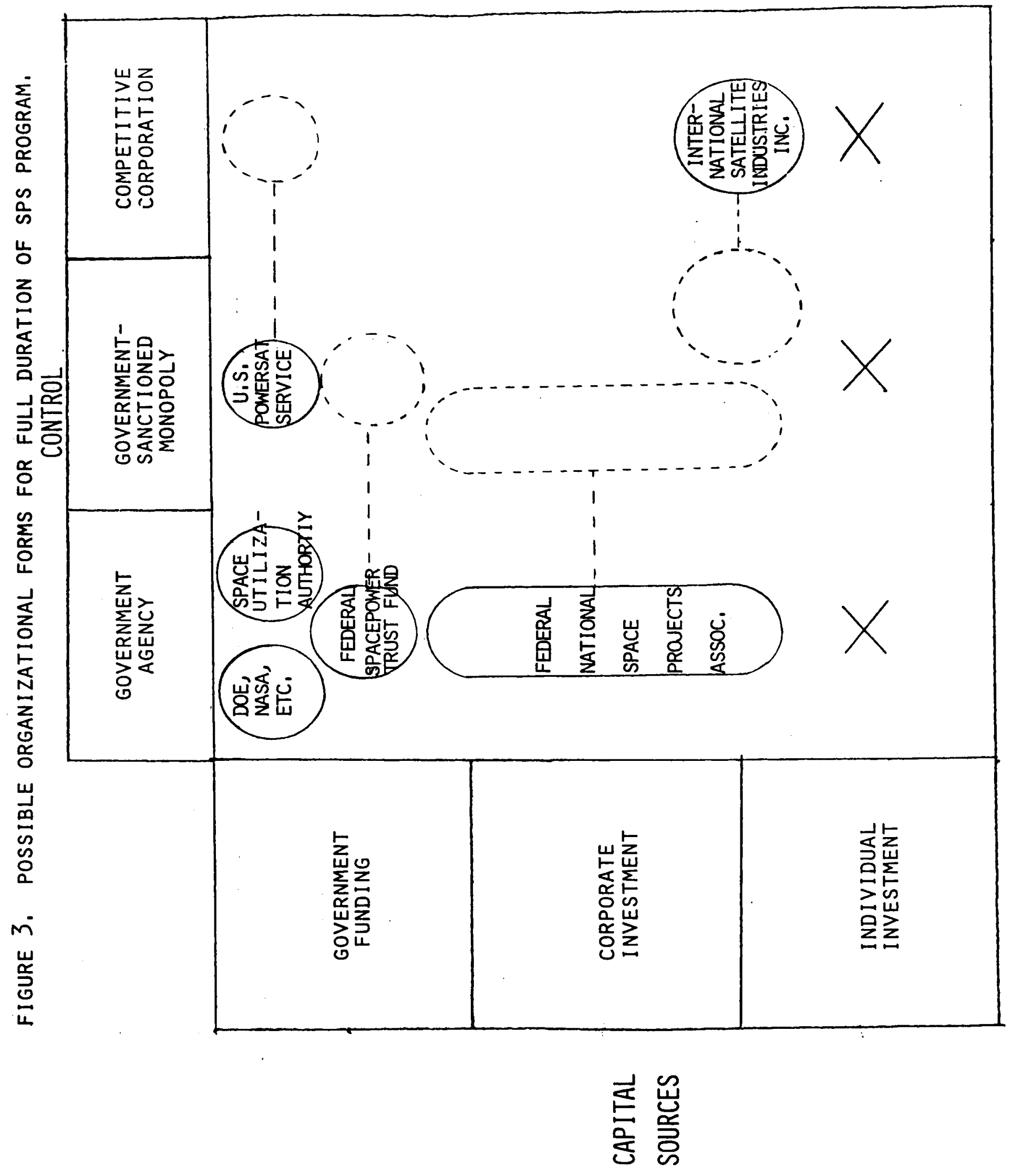


If we now consider the commercial implementation phase only, assuming that government agencies such as DOE and NASA have already provided the R\&D necessary over a period of perhaps 7 to 15 years, four possibilities arise. Funding and control are shown in Figures $4-A$ and $4-B$ for these four:

7. A government-chartered monopoly, here designated "Solar Satelite Corporation" in analogy to the Communications Satelite Corporation, with ownership divided between the general public and the utilities industry.

8. The consortium model, in which one or more consortia of aerospace companies, high technology companies, engineering companies, and management companies undertake to construct SPS's using the technology base developed by DOE, NASA, and others during the R\&D phases.

9. The corporate socialism model, analogous to the method of financing the Union Pacific Railroad and the development of jet air transport more recently.

10. The universal capitalism model, proposed by Louis o. Kelso as an economic reform permitting wider participation in the ownership of stocks, leading to a "Second Income" (dividends) for most workers. (9) (See Figure 4-B).

Any of the methods based on non-governmental agencies would be improved in their effectiveness and profitability by certain types of tax legislation, as discussed below.

Before describing each of these approaches to financing and managing an SPS program, we will first discuss criteria for evaluation of these alternatives. Then the detailed descriptions of each alternative scheme can be combined with discussions of the merits and liabilities of each approach.

\section{CRITERIA FOR EVALUATION}

A meaningful comparative evaluation of alternative financial and management approaches must be based on a common set of criteria applied across-the-board. Five general categories of criteria were considered in this preliminary assessment: economic, political, military, societal, and technological.

Economic criteria. The sine qua non for an organization proposing to undertake the sPS program is the intrinsic feasibility for that organization to obtain the level of funding needed. Because of the taxing authority of the federal government and the size of the GNP, it is clear that any government-owned scheme which can draw on the general tax funds of the federal government is--at least in principle--capable of acquiring the necessary capital, either by direct appropriations or by borrowing against future revenues. That private enterprises can obtain financing ior such large single projects as the commercialization of power 


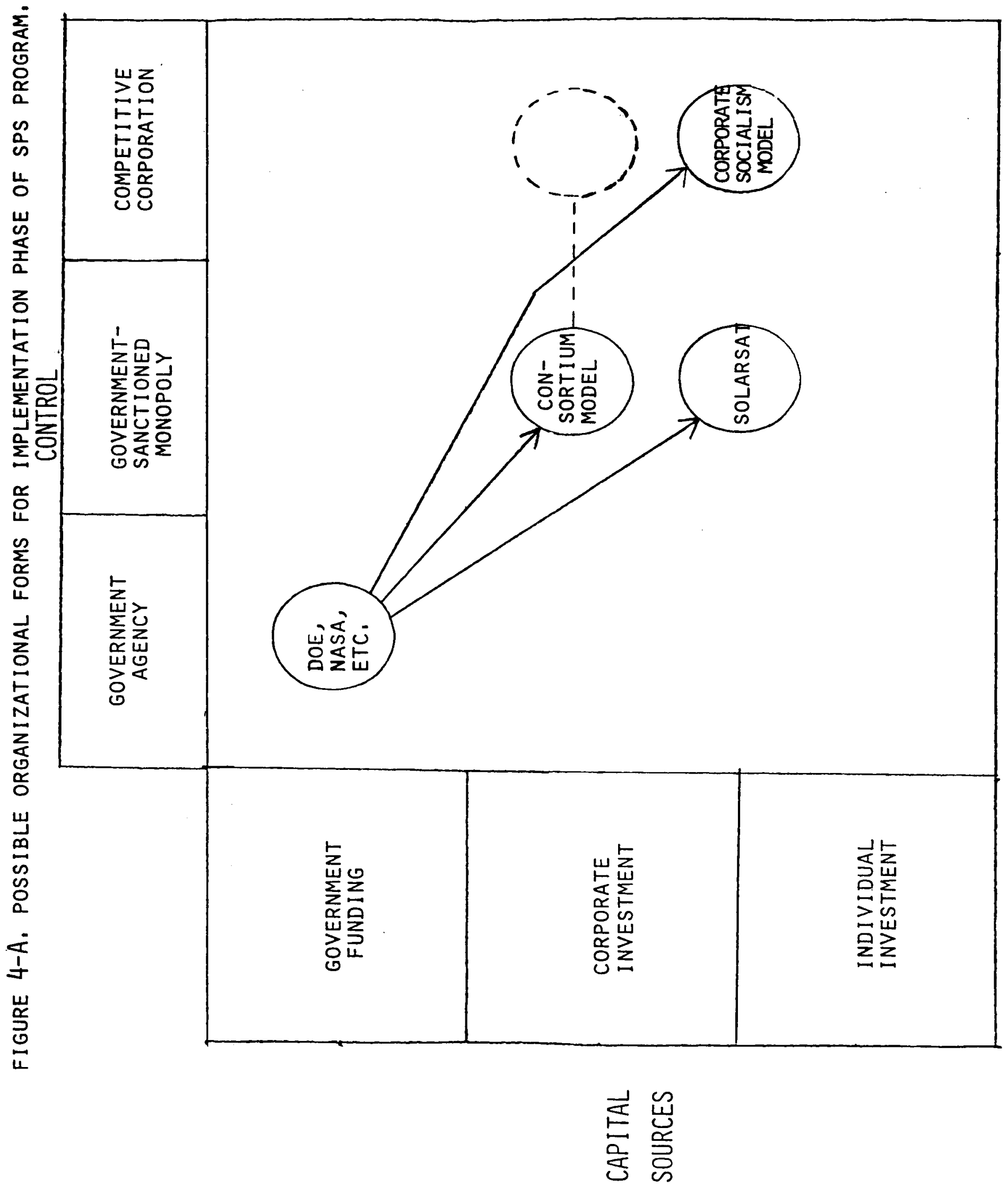




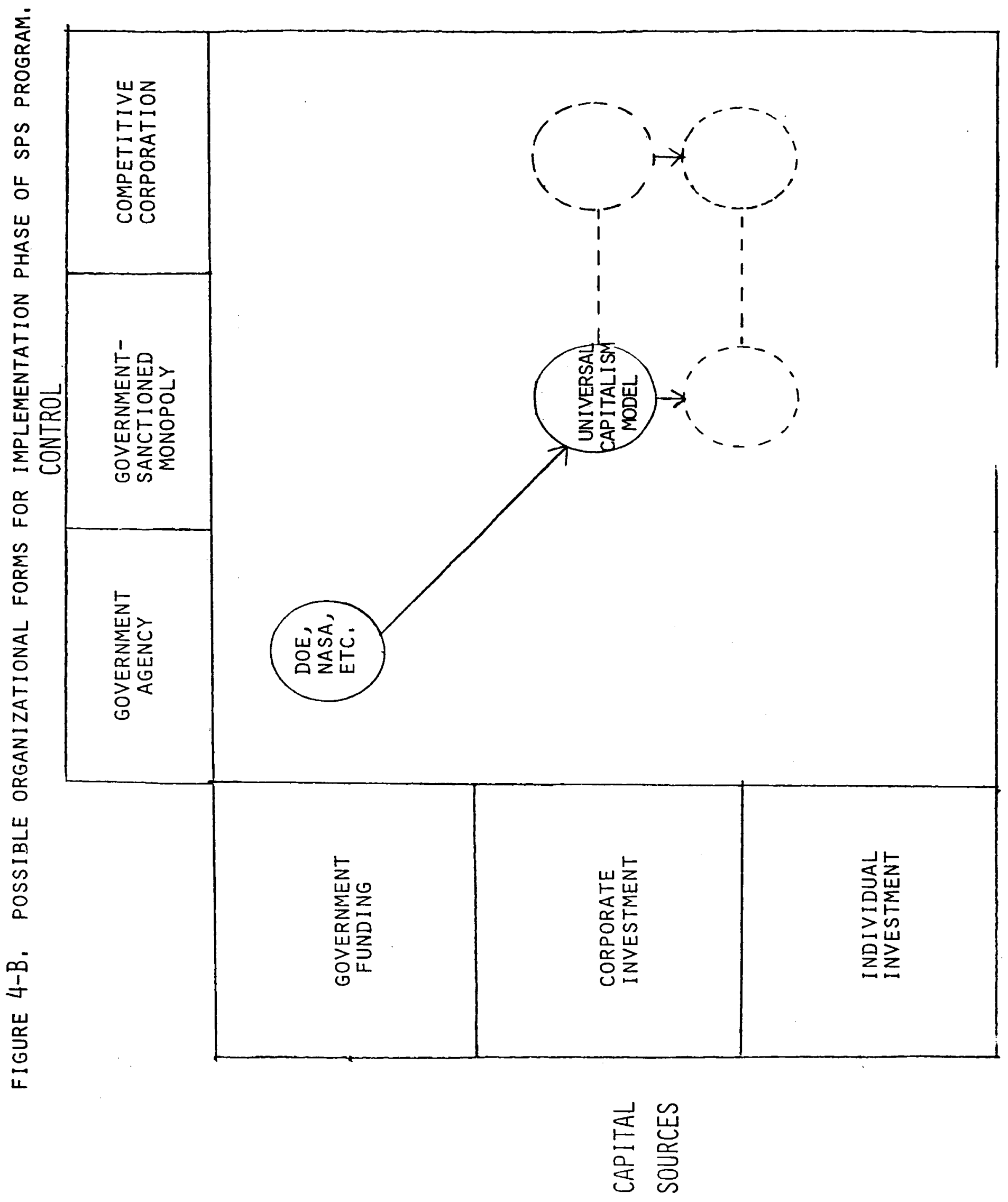


satellites is somewhat less clear, although if the risks are perceived to be reasonable, even large sums of capital can be obtained privately.

In view of the high front-end costs prior to deployment of the first commercial SPS, financing of the program must be organized so as to provide a near-optimum distribution of risks and rewards in order to give maximum assurance that required capital funding will be available when needed. In a program as large and as long as SPS, costs may escalate, requiring supplementaI funding beyond the original projections. It should also be anticipated that as the program progresses successfully, additional funding and venture capital will become available to the project as the risks decrease, and provision should be made for broadening the base of participation.

Economic viability of such a large enterprise depends critically on efficient management. The management of the SPS program must provide for long-term stability and continuity of purpose, while maintaining flexibility to permit rapid responsiveness to unforeseen changes in the economic, political, societal, and technological environments which are certain to occur during a multi-decade program. This requires that the SPS program management be structured from the very beginning to interface effectively with the multitude of governmental agencies involved with SPS. Efficient management will also require an organizational structure which permits unusual incentives and rewards so that the SPS program can attract and hold the most creative and aggressive management and technical talent available.

The economic viability of an SPS program will be greatly enhanced if the available market for power sateliites is international in scope. An organizational structure which can permit foreign funding as well as domestic funding would spread the risks wider. Such support, however, is unlikely unless the potential foreign customers could exercise significant control over either the power satellites from which they will obtain power or over the organization which owns the power satellites. The United States, for 1ts part, would be reluctant to rely on an SPS which was not in its own control. These considerations suggest that, whatever SPS organizational form is implemented, it would be most viable if it sold SPS's outright rather than selling power. Financing of such purchases could be arranged in other countries by standard methods of capitalizing the electric utility industry or by loans from international sources such as the World Bank or commercial banks.

The potential for an SPS program to make a rapid and significant contribution to U.S. energy needs has important economic ramifications which are difficult to estimate quantitatively. 
These include improvements in the U.S. balance of payments, enhancement of employment opportunities by creation of a new industry, and acceleration of new technological developments which in the past has always stimulated new economic growth.

Since an SPS program will necessarily involve a great deal of new technological development, the economis viability of the organization will be enhanced through vigorous marketing and licensing of patent rights for inventions not directly related to the SPS.

The economic criteria described above may be summarized as follows:

$$
\begin{aligned}
& \text { E-0. Ability of the organizational form to obtain } \\
& \text { the capital necessary for program implementation. } \\
& \text { E-1. Appropriate distribution of risks and benefits. } \\
& \text { E-2. Possibility for wide participation. } \\
& \text { E-3. Continuity, stability, and flexibility of } \\
& \text { management, including freedom to determine } \\
& \text { personnel policies. } \\
& \text { E-4. Possibility for foreign sales and participation. } \\
& \text { E-6. Ampact on U.S. energy supply. }
\end{aligned}
$$

Political criteria. An enterprise as large as an SPS program would have to have broad support from the public, from Congress, and from the administration up through the President and his staff, whether or not significant government funding were involved. Such support, it would seem, could be obtained most readily by arranging the financing and management so as to offer opportunities for the widest possible participation and gain as rapidly as possible. If present trends in voter attitudes should continue, the structuring of the sPs project must avoid all appearance of becoming the back yard of big government.

The nature and degree of international participation and of U.S. control over development and operation of the system will affect domestic acceptability of the program. Both government and private funding sources may be reluctant to commit risk capital to a venture amounting to a "give-away" of U.S. technological know-how to foreign investors.

International acceptability, on the other hand, would seem to require the opportunity for small developing nations to participate without total domination by the United States. Even among such small nations, the perception is growing rapidly that participation in space activities and their benefits will have profound impacts on their destinies. This is reflected in the recent increase by nearly fifty percent in the membership of the United Nations Committee on the Peaceful Uses of Outer Space (UNCOPUOS), 
mostly small one-nation-one-vote countries. Some of the small Third World countries are fearful that unilateral development of an SPS system by the U.S., the U.S.S.R., or a group of industrialized countries (such as ESA) would amount to a technological-benefits grab in which the rich get richer, and the poor get poorer. Whether or not these att1tudes are well-founded, their political repercussions would have a strong effect on support of an SPS program, both in Congress and in the administration, especially in the State Department.

The political criteria, in brief, are as follows:

P-1. Lack of obvious domination by "big government."

P-2. Protection of U.S. technological advantages.

P-3. Opportunity for Third World participation.

Military criteria. Both the space and ground segments of the SPS system are large, frail structures. The satelite portion is potentially vulnerable to space weapon attack while the rectennas are potentially vulnerable to terrorist action (as is any other centralized powerplant). While an attack on a powerplant located within the territory of a nation-state would presently be considered an act of war, it is not as clear that the same would apply to an orbital powerplant. This ambiguity may be aggravated by the fact that the sateliite portion of the system, being a generator of large amounts of energy, may involve military-related technologies and may thus be percelved as adaptable to military use. To enhance domestic and interrational acceptability of the program, it would seem that funding should come from sources, and be controlled through, channels with as little military identification as possible.

(At the same time, managament of the program should be organized so as to permit interaction with the Department of Defense and the Department of State to ensure (1) that national security implications of new technologies arising from the program are recognized and utilized in a timely manner; (2) that key technologies are not released or exported inappropriately or inadvertently; (3) that the vulnerability and defensibility of the Satellite Power System are thoroughly understood; and (4) that the consequences of sudden loss of some or all power satellites are thoroughly understood.)

One particularly sensitive military consideration affecting international acceptability is the potential destablizing influence of an SPS program on the U.S./U.S.S.R. strategic balance. As a beamed-energy device, an SPS could be considered to be in the same category as charged-particle beams and high-energy lasers. Because of the kinds of strategic weapons capabilities such devices have, they may upset the present balance unless they were deployed simultaneously by both superpowers. In any case, the financing and management of an SPS program should be arranged to provide 
adequate assurances and guarantees that no SPS would (or could) be used in a destablizing way.

\section{Summarizing the military criteria, then, we have: \\ M-1. Minimum identification with the military. \\ M-2. Assurance against destablization of strategic balance.}

Societal criteria. The sheer magnitude of an SPS program and the consequent necessity for disciplined and efficient management of finances, R\&D, and operations could lead to fears of creeping bureaucracy, elitism, and excessive concentration of power. An SPS organization should thus be structured to permit the widest possible participation of society, not only in the ownership (financing) of the enterprise, but also in management and employment opportunities. The success of widespread participation in this way depends on the institution and implementation of means for effective rewards and penalties for competence and incompetence, respectively, at all levels of the organization.

Excessive concentration of power within an SPS organization can be avoided in part by establishing the organization in a form which will simplify later divestiture of portions of the enterprise or, indeed, total abandonment of the SPS project if changed circumstances make SPS no longer desirable.

Candidate SPS organizations, of course, must be consistent with national and international principles. Outer space, like the oceans, is generally regarded as the province of all humanity. The ultimate legal matrix within which the SPS program must be formulated and operated is that of international law and the slowly growing body of space law. Clear guidelines are as yet scarce in this infant field; many of the elements of space law will follow rather than lead events. To remain within the developing framework of space law, the organizational principles for an SPS enterprise will have to observe general principles of reason and fairness, relying on historical legal analogies wherever appropriate. In cases of significant ambiguity, an SPS organization should be able to make its own judgements and act upon them without unreasonable delay.

The societal criteria, then, may be summarized as follows:

S-1. Widespread participation in management and employment.

S-2. Flexibility with respect to later divestiture or project abandonment.

S-3. Ability to act decisively within the changing framework of international space law. 
Technological criteria. During the lengthy period between initiation of a serious R\&D effort and on-line operation of the first SPS, numerous technological innovations should be expected. Some of these will come from outside the SPS program; others will originate within the SPS program and have major impacts in other areas of society. A prime necessity in organizing and operating an SPS program is to provide the means for encouraging and identifying these innovations, funding their initia? exploration, implementing their application within the SPS effort rapidly, and facilitating their transfer to other areas by vigorous marketin of patent licenses.

As growing numbers of power satelites are deployed over succeeding decades, initial designs and technologies will become increasingly obsolete. Adaptation of the program to new technologies will become ever more important and advantageous. If the SPS program is successful, it will generate large quantities of new investment capital. Significant reinvestment of this new capital in the creation of newer technologies could become a historically very important technological "bootstrapping" mechanism. Both the energy and the new knowledge produced will diffuse globally, regardless of how the SPS program was initially formulatej. In anticipation of this longer-range evolution, however, the initial organizational form should be structured to permit and encourage this bootstrapping process.

These technological criteria, in brief, are then:

T-1. Ability to foster, utilize, and disseminate innovative technology.

T-2. Ability to stimulate continuing technological development.

The diverse criteria discussed above are, in most cases, rather subjective; they are of widely differing importance in evaluating candidate SPS organizational forms. At this time, these criteria are perhaps more useful as design principles for an SPS organization than as standards for selecting, once and for all, the single best form. Far more study of the candidate forms is necessary as yet before such a decision can be made. 


\section{DETAILED DESCRIPTIONS AND PRELIMINARY EVALUATION OF ALTERNATIVES}

1. Existing government agencies. In principal, an SPS program could be implemented by existing agencies including Department of Energy and NASA. The Reference Design cost estimates assume about $\$ 40$ to $\$ 45$ billion over the first fifteen years for verification and for DDT\&E, with a peak expenditure of about $\$ 7$ to $\$ 8$ biliion in one year. Such a level of effort is somewhat below the peak expenditure levels during the Apollo program (with due allowance for inflation since then). The R\&D phase of the program, it would seem, could be managed and financed in this manner, assuming sufficient political support for the program.

A significant potential benefit to using this approach during the R\&D phase is the possibility of synergisms with other space programs, including large space construction, large solar power systems, and advanced orbital transfer propulsion capability required for advanced communications and navigation systems in the late 1980's--early 1990's timeframe. (2) A liability of this approach is resistance from the space science community to the use of the space Shuttle for space industrialization programs.

Actual implementation of the SPS program through these channels, however, would be much more difficult. The Reference Design cost estimates suggest costs rising rapidly from about $\$ 12.9$ billion during the first year to $\$ 29.2$ billion in the fourth year, dropping to $\$ 24.5$ billion in the fifth year, rising gradually over 30 years to a peak of $\$ 32.7$ billion before tapering off to about $\$ 9.8$ billion annually for maintenance and repair thereafter. Neglecting interest costs, the power satellites would have to be sold outright for more than $\$ 2500$ per kilowat of busbar capacity if implementation were not to be a burdensome tax liability.

Significant liabilities to such an approach include the civil service status of existing government agency employees; opposition to tax support of large, expensive, and unproven technologies; the placing of government agencies in direct competition with private industries providing comparable services (viz., construction of generating equipment for the utilities); charges of governmental usurpation of a major sector of the economy; uncertainty of long-term stability of management and purpose; inefficiency and inflexibility; slow responsiveness to external changes in society and technology; restriction of international participation due to direct involvement of the U,S. government; lack of participation by corporations and individuals domestically. 
2. New government agency--"Space Utilization Authority." Grodzka ( 6 ) has pointed out the parallels between the economic conditions prevailing during the 1970's to some of those in the Depression during the $1930^{\prime} \mathrm{s}$. One of the most successful programs of the New Deal was the creation of the Tennessee Valley Authority which deliberately set out to transform the eccnomy of perhaps the most depressed area of the nation at that time. As a result of those efforts, the region served by TVA has the highest proportion of jobs in manufacturing of any region in the nation. The original program cost about a quarter of a billion dollars then. Grodzka argues that using tax dollars for the creation of new technologies and new industries of high leverage (as the space industry has proven itself to be) can stimulate the economy far more effectively than equal amounts spent in welfare programs, especially since an SPS program would create a large number of new jobs for unskilled and semi-skilled workers (particularly in the manufacture and assembly of rectenna components and in rectenna construction).

Placing an SPS program within a newly formed agency would certainly solve many of the internal political problems such a program would face within existing agencies. Management practices could be tailored to the long-term goals of the project far more effectively than would be possible within NASA or DOE where the wide range of goals and research foci would dilute managerial attention to SPS. But most of the liabilities listed above for existing agencies would still remain. Figure 5 shows the flow of authority and of funding required for the creation and operation of SUA. The diffuse and indirect nature of the benefits to the taxpayers is a major obstacle for SUA as well as for DOE/NASA as a potential sPS organization.

Depending on the degree of independence afforded SUA by its charter, it could behave either like a government agency or like a government-sanctioned monopoly. Its lack of direct accountability to the public, however, is a major difficulty; TVA has itself experienced some difficulties in recent years because of local opposition to specific dam projects and nuclear powerplant construction projects, in which the residents of the affected areas felt their viewpoints were not sufficiently considered.

Over the decades, the increasing size of SUA would pose significant problems of concentration of power. For SUA to break up into several smaller units, each of them remaining a government agency, would provide little improvement. Should SUA wish to sell off a division to one or more private corporations, it would be difficult to ascertain the correct valuation. Alternatively, if an entire division were to be transferred to the private sector by issuing shares and selling the division of through the stock market, a tremendous liquidity problem would ensue, since 


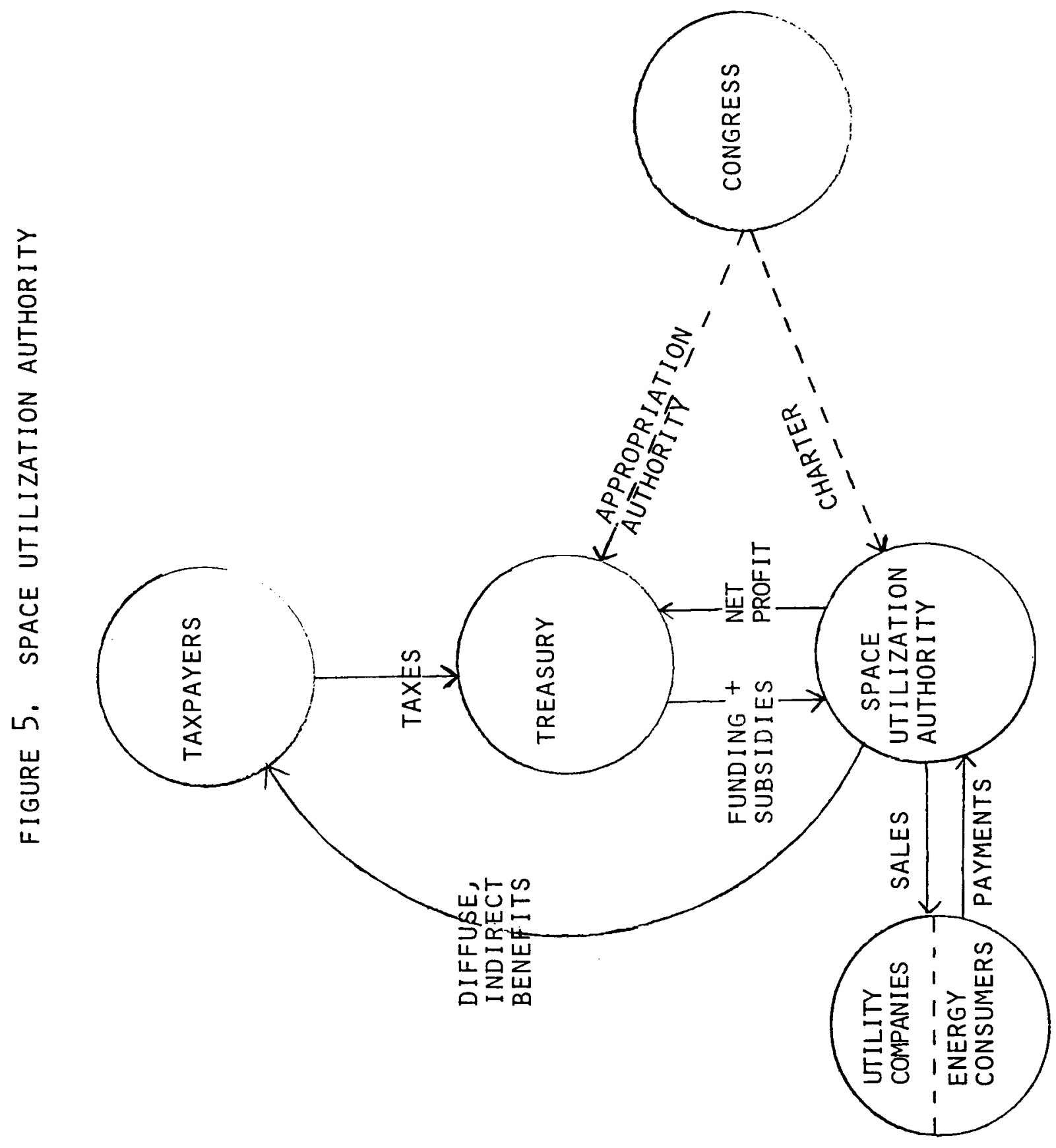


the total capitalization of SUA could eventually exceed that of the largest corporations today. It would be difficult to imagine the government opening up the SPS market at that time to competition from new private companies because of the government's vested interest in SUA.

\section{The taxpayer stock corporation--"U.S. Powersat Service."}

Fredericks and Stutzke initially proposed this concept (7). The flows of funding and authority are shown in Figure 6 . One fundamental objection to the two schemes discussed above is the coercive nature of funding a controversial project by general taxation: the decision to invest tens of billions of dollars would have been made by th Executive and the Congress. In order to permit a more direct voice in the operation of an SPS organizaticn supported by public taxation and to reduce the sting of being forced to financially support a project to which many taxpayers may be opposed, Fredericks and Stutzke proposed the creation of a taxpayer stock corporation.

The basic idea is to create a quasi-public corporation by act of Congress to implement the SPS program. Funding would be provided by a specific appropriation each year, but every taxpayer would receive some number of shares of stock in the corporation each year in proportion to the fraction of his or her taxes which had been appropriated to the corporation in that year. Taxes directed into the program early in the life of the project would, in effect, purchase more shares per dollar than would tax dollars allocated to the project near fruition on the basis of a formula price for the stock of the corporation. Such a formula price could be computed on the basis of the discounted value of the anticipated future earnings per share.

Since shares in the U.S. Powersat Service could be freely traded on the stock market, taxpayers opposed to the project could "redeem" at least some fraction of their taxes spent on the project by selling the shares issued to them by the Treasury after filing of their income tax returns. Similarly, pensioners whose investment time scales were too short to anticipate significant earnings from their shares could obtain short-term benefits from current taxes. For those taxpayers who support the SPS program would have the opportunity to purchase more shares in anticipation of later rewards.

While USPS would be subject to significant control by congress during the R\&D and early commercialization phases, the shareholders would elect the Board of Directors from a very early stage. As the system matures during the commercialization phase, and no further appropriations from Congress are necessary, the Directors would be answerable only to the shareholders, just as in conventional private corporations, creating significant pressures on the management of the SPS program to maintain profitability and accountability. A further advantage would be foreign financial participation from the very start, as well as the diffusion of 


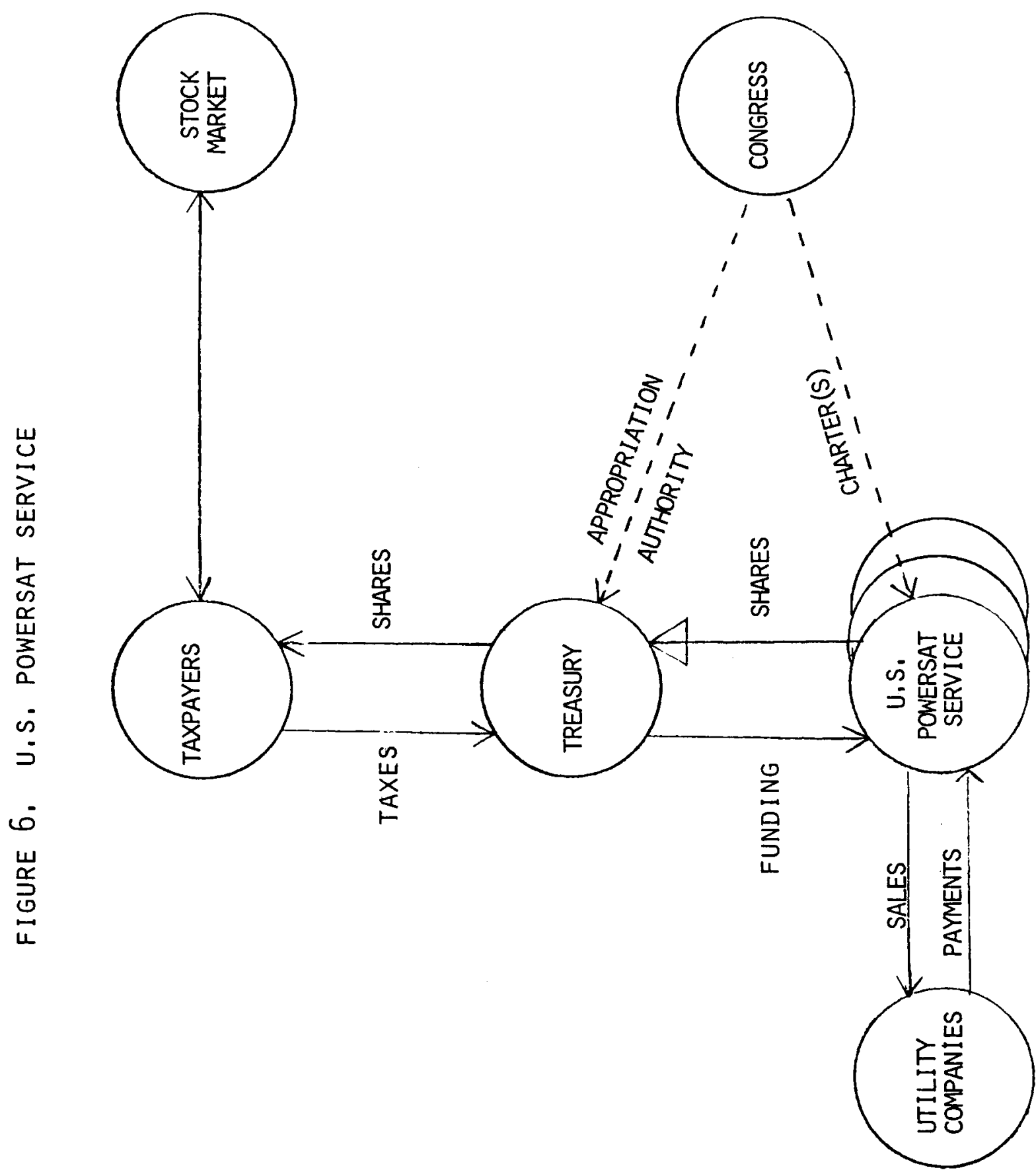


capital ownership among the general population, which would have beneficial effects throughout society and the economy. (See the discussion of the universal capitalism model further below for details.)

Whether or not the taxpayer stock corporation is adopted specifically for the SPS program, it is a new social invention of some merit in its own right which could be considered for other long-term projects as well which are expected to provide long-term economic benefits. (Candidates might include largescale hydraulic projects, Ocean Thermal Electric Conversion power systems, or smaller scale space industialization options.)

Because of the novelty of this idea, it is somewhat difficult to evaluate how successful it would be in terms of the criteria discussed in the previous section. If public confidence in the success of the entire program were low, the actual stock market value of the shares issued would be very low; the only current benefit to taxpayers who did not wish to keep their shares would be to claim a capital loss upon selling off their shares, seriously hampering the political acceptability of the concept.

\section{Trust fund supported by energy taxes--"Federal} Spacepower Trust Fund." During the last three decades, the federal government has provided most of the funding necessary for a domestic project comparable in magnitude to an SPS program, viz., the Interstate Highway System. This was motivated by the desire of Congress to improve the efficiency and versatility of the transportation infrastructure; by the military for possible use in a mobile ICBM system; by the automobile and petroleum industries as a means of expanding their markets; and by the middle-class dream of owning their own individual home with a garden.

The method of financing chosen was to impose a modest tax of a few cents per galion on motor vehicle fuels across the nation. Private individuals and trucking companies have contributed the majority of the funding; state governments have contributed some stated percentage of the costs of each project and have assumed the burden of maintaining the system. The beneficiaries have been considered to be the motorists who have contributed most of the funding, in the form of better highways, greater convenience, and increased options in choosing where to live and where to work.

An SPS program could be supported analogously. A modest tax on each unit of energy consumed (particularly electrical energy) could be channeled into a federal trust fund to finance the R\&D phase and the construction start-up costs. The longterm benefits to energy consumers who paid the taxes into the trust fund would be reduced energy costs for the SPS relative to other energy alternatives not iniplemented by the federal ocvernment. Flows for this sheme are shown in Ficure 7 . 


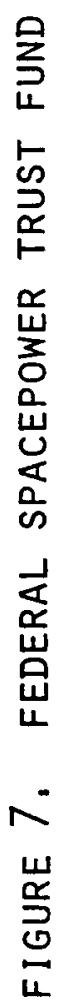

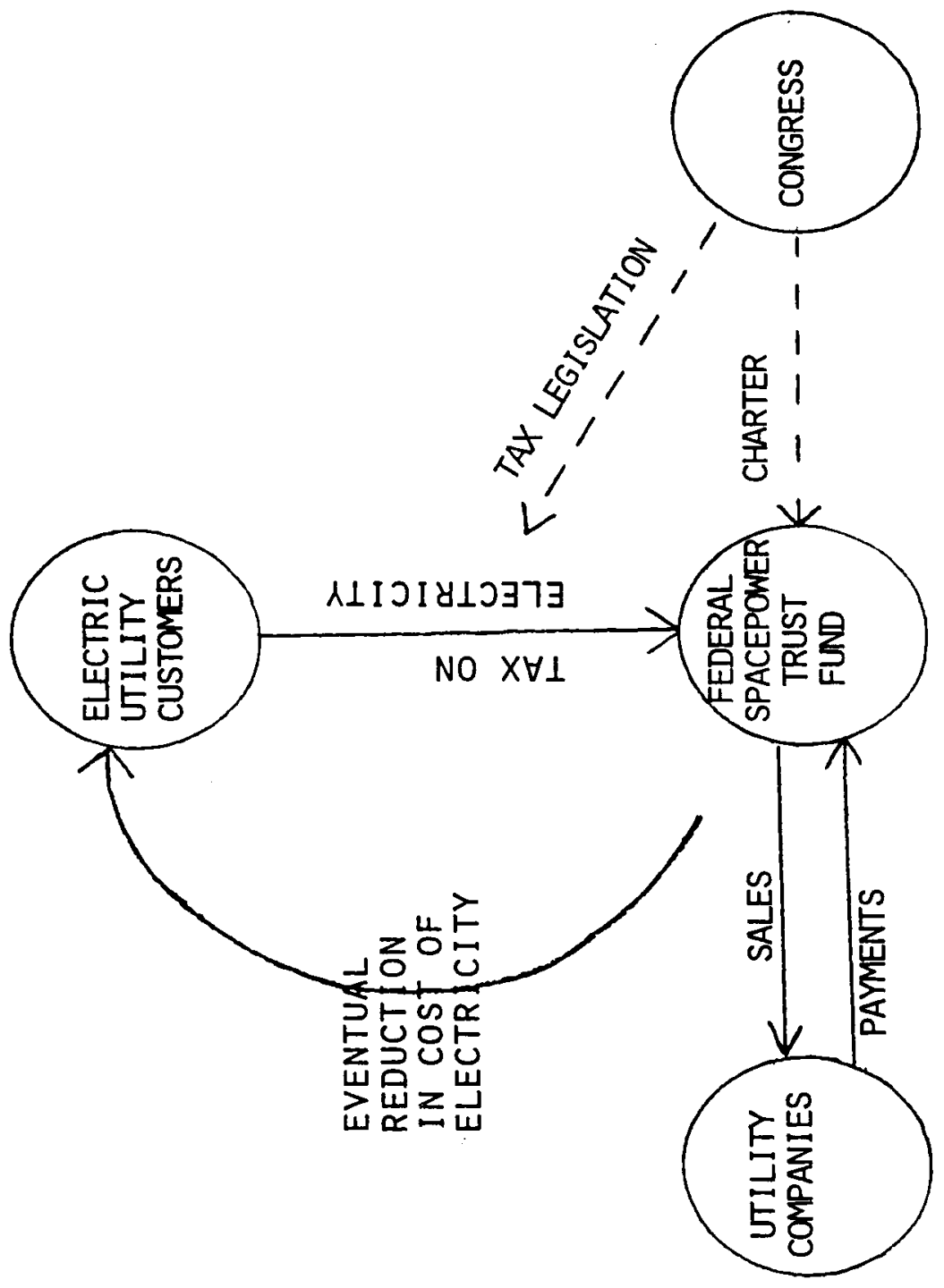


Utility rates are regulated at the present time by each of the states. In most cases, utility companies are prohibited from charging more than token expenditures for R\&D on future energy technologies to current rates. Federal legislation overriding these state policies and practices would be required, possibly triggering a "states rights" battle.

Total U.S. electrical production in 1974 was $1.865 \times 10^{12} \mathrm{kwhr}$. Assuming a tax of 2 mills/kwhr on electricity delivered to consumers, more than $\$ 4$ billion per year could be collected during the $1980^{\prime} \mathrm{s}$ by this means. Comparing this figure to the present value for the P\&D program as shown in Table I-A, it is clear that the necessary funds could be accumulated (at interest) in a period of less than six years before starting the R\&D program; if the tax were at a lower rate or if it began concurrently with the R\&D program, the tax would have to continue for as long as ten years. At present rates for electricity, this tax would affect the cost to consumers by less than $5 \%$.

Some of the advantages of this approach include the fact that it places the burden of cost and risk on those who use the most energy and thus push the demand for new generating capacity the most. Disadvantages include all those mentioned earlier for government agencies.

5. Long-term government bonds--"Federal National space Projects Association." Long-term bonds would provide an alternative with greater freedom of choice for investors than funding by either general tax revenues or energy user taxes. The Federal National Mortgage Association ("Fannie Mae") is a government-chartered corporation which provides mortgage funds for homeowners through long-term bonds traded on the bond market. The Bonds are issued at a price significantly lower than their maturity value; the difference between these two prices corresponds to an interest rate over the life of the bond which reflects the investment community's sense at the time of issue of the medium-to-long-term. interest rates. The bonds themselves are subsequently traded during their life at a market price which declines when interest rates go up to provide an effective yield equivalent to competitive interest rates. As maturity approaches, the market value approaches the maturity value to maintain the competitive position of the effective interest rate.

Fannie Mae is self-supporting; bonds are redeemed at maturity from the principal and interest payments of mortgage borrowers. The government assumes some risk in case of defaults by a significant fraction of the borrowers. Speculative investors absorb the gains (or losses) due to changing interest rates during the life of the bonds. 


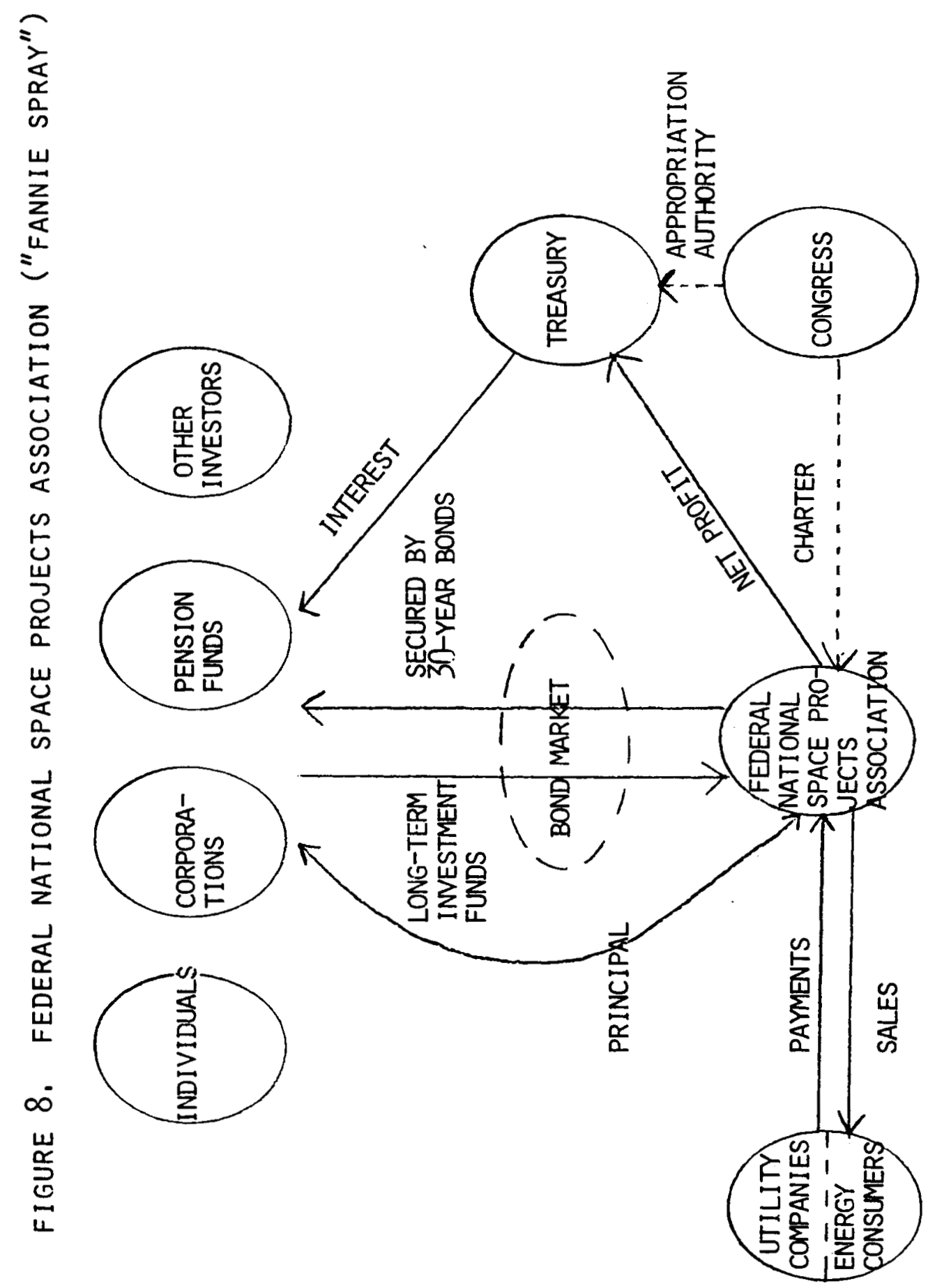


The flows of authority and of funding for a Federal National Space Projects Association ("Farnie Spray") are shown in Figure $\varepsilon$. Fannie Spray would be self-supporting if the SPS project came to fruition; otherwise, the Treasury would eventually have to absorb the costs of redeeming the bonds issued to finance the R\&D phase. To the extent that inflation exceeded the effective yield of the Space Bonds, the ultimate cost of an abandoned SPS program to the taxpayers would be lessened in comparison with financing from current taxes. On the other hand, Fannie Spray could repay some of the costs of the R\&D program by vigorous marketing of patent licensing rights acquired during the R\&D phase. (This would also apply to NASA, SUA, or USPS were sufficient emphasis given to this kind of marketing.)

Adequate funding of the SPS R\&D phase could probably be assured if the effective yield on the Space Bonds were sufficientiy high at date of issue to compete with other investments in the bond market. Assuming a $6 \%$ per annum real interest rate (before inflation)--a very severe penalty for the SPS program--the total value of bonds plus interest outstanding at the end of the $R \& D$ phase would be $\$ 68.29$ billion. (See the compounded value column in Table I-A.) Assuming the bonds were issued for 20-year maturit: (with the option for Fannie Spray to redeem bonds prior to maturiiy date), this total indebtedness could be paid for by charging "licensing fees" of $\$ 5.954$ billion each year during the first twenty years of the commercialization phase. In the Reference Design timetable, this would imply a cost to the utility companies of $\$ 33.482$ billion for $10 \mathrm{GW}$ of generating capacity. (See compounded value column in Table I-B; add the above licensing fee to obtain the capital sum to be financed by the utility.) Assuming the same $6 \%$ real interest rate per year, the net revenues would amortize this total cost over about 17 years, a time scale which seems to stretch credulity even in the utility industry. Either Fannie Spray would have to significantly reduce the cost per kilowatt for SPS below the Reference Design, or the Space Bonds would have to be stretched to thirty years allowing a lower licensing fee, or the rate of construction and sales of power satellites would have to be increased above $10 \mathrm{GW}$ per year. (Any of these approaches would improve the performance of any financing scheme discussed here.)

Compared to the taxpayer stock corporation, Fannie Spray would be less accountable to the taxpayers. Psychologically speaking, Space Bonds would compete directly with other needs for capital funding in a way that taxes do not. On the other hand, since bond financing would not appear as a line-item in the federal budget, it would be far easier to obtain public support for this method of financing than for direct appropriations to an SPS proE-am.

Unless the charter of Farnie spray were organized along Iines similar to private enterprise corporations (as is the case--to a certain extent--with pannie Mae), it would be hampered by the management liabilitius of govemment agencies in general. 
6. The staging company approach--International Satellite Industries, Inc. Thus far, the only proposal of which we are aware for private funding of an SPS program all the way through from R\&D to commercial implementation is the staging company concept of Basler. (8) The staging company concept recognizes the essential qualitative differences between the R\&D and the implementation phases of an SPS program. The principal challenge to private financing is the length of the $R \& D$ phase during which large expenditures are required without any hope of revenues. Once an SPS program has been demonstrated to have low economic and technological risks, i.e., once the utility industry can be assured that an SPS ordered at a certain time can be delivered with reasonable certainty on or before some specified date at a cost known within narrow uncertainty limits, implementation can proceed at a rapid pace with normal financing methods.

How can the $R \& D$ phase be funded privately if no revenues can be expected for ten or fifteen years? The idea or the staging company is based in part on the economic value of new technology itself. Instead of relying on dividend income during the $R \& D$ phase, investors who are willing to be somewhat speculative could expect capital appreciation of their shares in a staging company: the accumulation of technological advances and of patent rights would make possible future profits whose anticipation would push up the value of the staging company's shares.

International Satelite Industries, Inc., has already been incorporated (August 3, 1978, in the State of Delaware), as a partially closed-end non-diversified management investment company. (In effect, ISI is a kind of mutual fund.) A conventional mutual fund would distribute most of its dividend earnings and capital gains distributions from its investments to its shareholders. ISI would instead spend substantially all of its income on R\&D contracts directed toward power satellites. To stretch the funds available from its portfolio income, ISI intends to contract for R\&D primarily with companies willing to share the costs of R\&D as joint venturers. Patent rights directly related to SPS would be controlled by ISI; other patent rights could be reserved to the joint venturers or shared with ISI. The joint venturers would receive options to purchase ISI stock after its conversion from an investment company into an operating company.

As originally envisioned by Basler, the staging company would invest primarily in aerospace companies and other high-technology companies likely to profit from space industrialization. Through the R\&D process, ISI would gain significant insight into the prospective profitability of such companies. ISI would then be able to make its investment decisions with a high degree of confidence. The market's appreciation of ISI's confidence in the future profitability of such companies would exert strong upward pressure on the value of shares in which ISI had invested, increasing the value of the staging company's portfolio and thus the value of

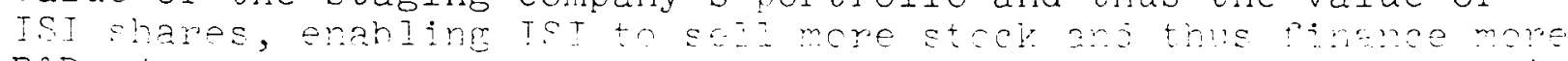
R\&D. (Figure $9-A$ shows the flows for the stagine company phase.) 


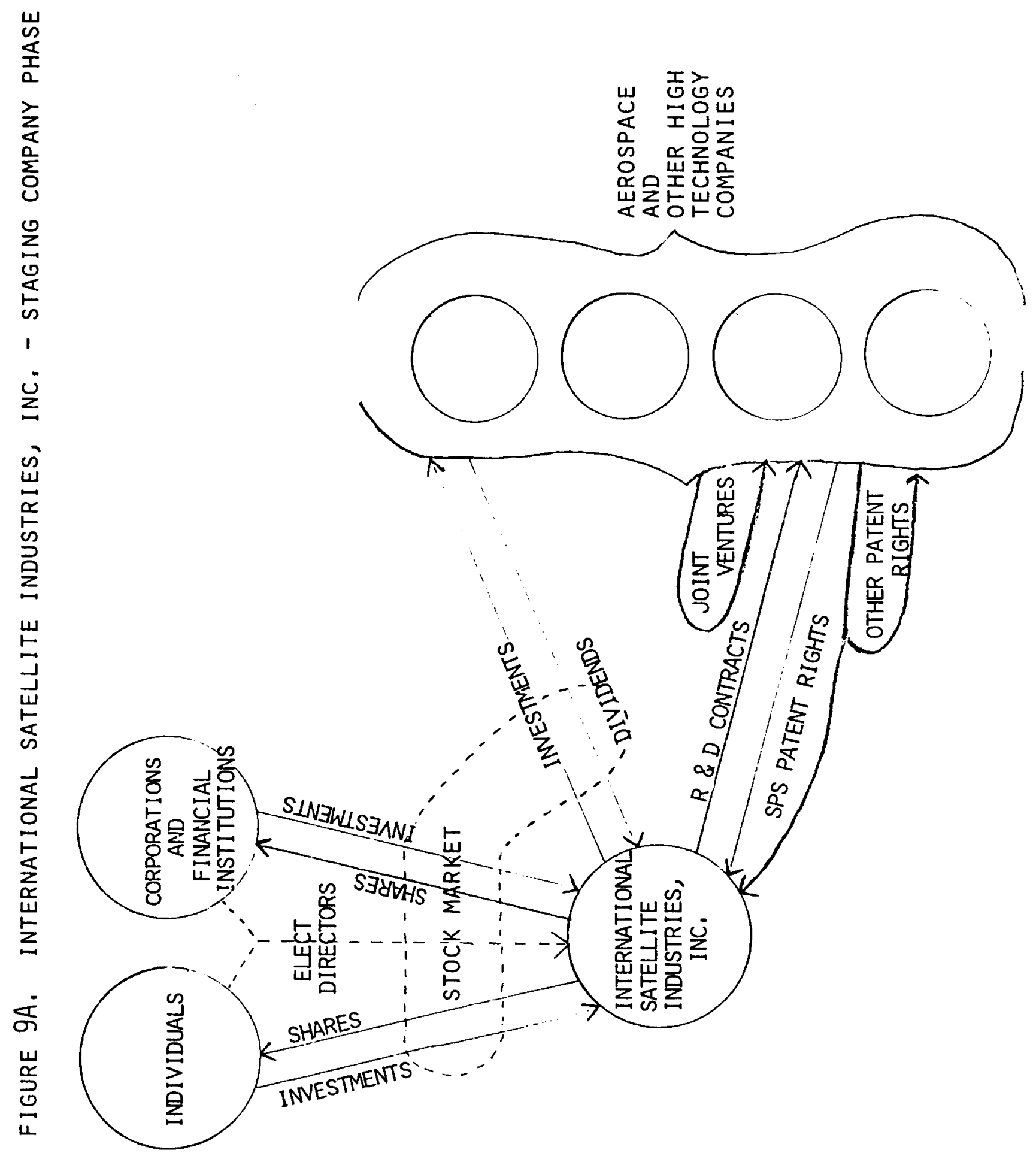


(This mechanism is not described in ISI's preliminary prospectus draft; it is not very likely to play an important role in ISI's investment decisions during the first year or two, but should become increasingly significant.)

Once the prospect for successful commercial implementation of an SPS program is assured to the satisfaction of ISI's stockholders, the company would convert into an operating company and commence space operations using more conventional financing methods including advance sales of power satellites to utility companies. In the operating company phase, the relevant flows would be as shown in Figure $9-B$.

As a private enterprise, ISI would be free of many of the disadvantages of government agencies. From the very start, its funding would be international in character, and it wolild be very easy for ISI to create subsidiaries in other countries as necessary or convenient to become fully multinational, all without the necessity of lengthy state Department negotiations as would be necessary for an SPS organization based on government agencies. ISI would also be far more free than a U.S. government agency to select an equatorial launch site for its operations, with significant savings possibilities due to the improved performance of space transport to geosynchronous equatorial orbit. Sales of power satellites and of maintenance services to foreign countries could be facilitated by the use of subsidiary or affiliate companies incorporated in the customer nations.

Perhaps the major advantage of the staging company approach as far as early implementation of an SPS program is concerned is its ability as a private company to proceed without waiting for widespread political support prior to a go-ahead from Congress. At the same time, the magnitude of the required R\&D effort may strain the available capital sources for speculative investments. Yet this would encourage ISI to aggressively seek the most innovative and inexpensive design approaches to an SPS system. Should the ISI model show even partial success, it would provide a valuable new model for financing long-term projects such as Ocean Thermal Electric Conversion which are presently beyond the reach of private investment and lack sufficient political support for substantial federal funding.

In Figure 3, ISI is shown as a competitive corporation. Should sufficient speculative investment funds be avallable, more than one staging company may be formed, each following a slightly different program toward SPS commercialization. It seems unlikely, however, that the stock market could support more than one SPS staging company in the near future, so that ISI is likely to be alone in the field until commercialization approaches very closely. The patent rights secured by ISI would serve to preserve a very strong competitive edge for the original staging company which took the long-term, early risks. 
$w$
s
$\frac{1}{2}$
2
2
2
$\vdots$
0
0

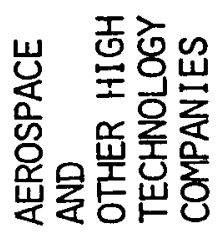

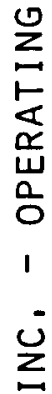

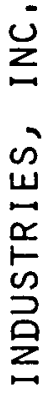

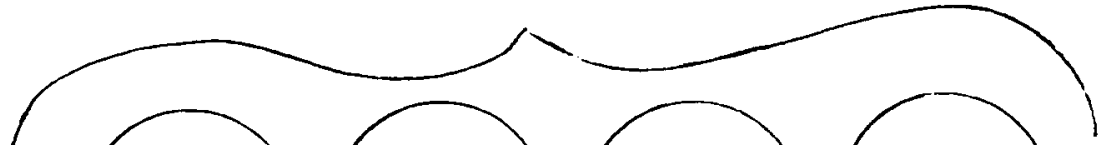

㞾

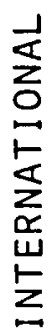

(

实出倠
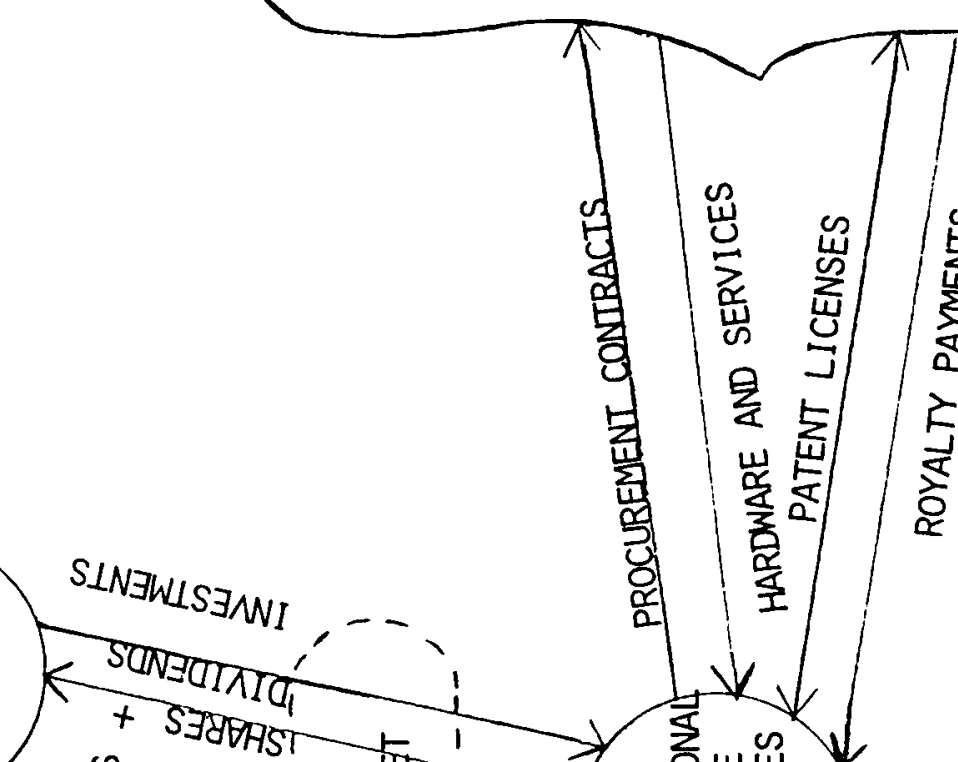

悬 怠
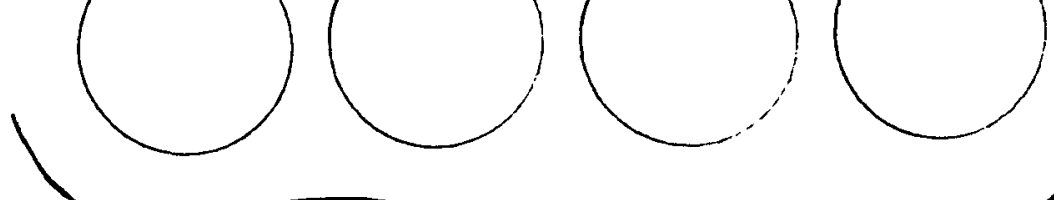

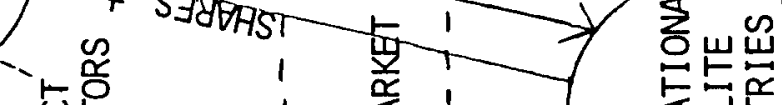

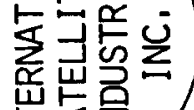

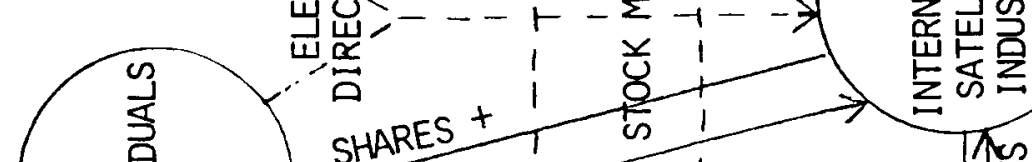

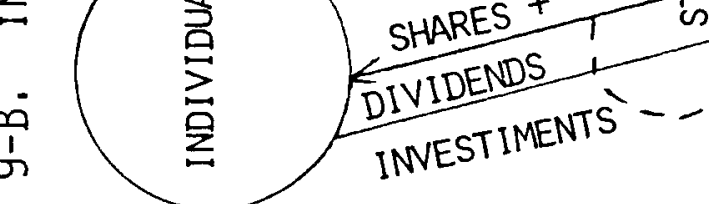

w

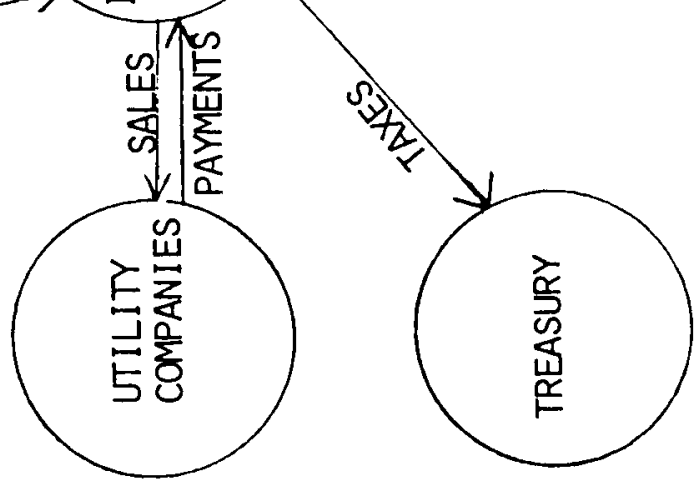


7. Government-chartered monopoly--"Solar Satellite Corporation." In the early $1960^{\prime} \mathrm{s}$, the success of several experimental communications satelites demonstrated the feasibility of establishing global communications services by satelilte. The problem of implementation then was to find a way to finance and manage a novel system within the framework of an existing and highly regulated industry, recognizing that an indeterminate number of years would be required before economic break-even.

The response to this opportunity and challenge was the Communications Satellite Act of 1962, signed into law by President Kennedy in August 1962. This Act authorized the creation of a private corporation, subject to governmental regulation, to establish in cooporation with entities from other nations a commercial communications satelite system on a global scale. As such, COMSAT was created as an instrument of national policy but not an agency of the U.S. government.

COMSAT was incorporated in the District of Columbia on February 1, 1963. The enabling act did not guarantee funds invested in the stock of the Corporation, the payment of dividends, or the profitability of the venture, but it did include a comprehensive plan for the conduct of the business of COMSAT, including government supervision of some matters that are not ordinarily subject to such control in the case of other communications common carriers in the U.S. The President was to approve COMSAT's Articles of Incorporation, to exercise authority over the relationships of COMSAT with foreign governments and entities, and to appoint three of the fifteen Directors of the corporation for three-year terms of office. The Federal Communications Commission was required to regulate COMSAT, including its rate structure.

In any offering of common stock, COMSAT was required to tender $50 \%$ of the isslie for purchase by communications common carriers authorized to purchase such shares by the FCC. Shares not purchased by authorized carriers could then be offered to the general public along with the other $50 \%$ of the issue. The initial offering of $10,000,000$ shares at $\$ 20$ per share was made in June, 1964. A total of 163 authorized carriers subscribed for the reserved 5,000,000 shares, the remaining 5,000,000 being sold through registered brokerage firms acting as underwriters, raising a total of $\$ 200$ million in initial capitalization.

The common carriers vote their shares to elect six Directors of COMSAT for a one-year term, and general public share-holders elect six more Directors for a one-year term. Each of the fifteen Directors has the same obligations to the corporation and to all its shareholders, regardless of the constituency electing or appointing them.

Although no dividends were paid on shares of COMSAT until the fourth quarter of 1970 , the market price of the shares rapidly soared above $\$ 50$, purely on glamor. ComsAT has faid quarterly 
dividends ever since, and at the end of 1977 showed a total shareholder's equity of about $\$ 355$ million; with net income for the year of $\$ 32.5$ million. With 8 million shares outstanding (the rest having been repurchased by COMSAT), equity per share was $\$ 44.38$. Operating revenues were $\$ 168.2$ million. ( 10 )

In August 1964, an international entity was formed for the purpose of establishing and managing the global satelite communications system. INTELSAT, the International Telecommunications Satellite Organization was established by multinational accords, under which each nation wishing to participate in the system delegated an entity (either a government agency or a chartered corporation) to act as its representative. As a natural "first among equals," COMSAT was contracted by INTET.SAT to manage the system, with INTELSAT collecting monthly bills for dues and use charges. Presently INTELSAT has 600 satellite pathways providing direct satellite communication services to more than 85 nations; landlines and microwave links extend these services to more than 120 nations. (Figure 10 shows the relationship of COMSAT to the U.S. government and to INTELSAT and other nations.)

A similar organizational arrangement could be used for the commercialization of an SPS program. Because of the much larger R\&D costs anticipated for SPS than for the communications satellites, it is unlikely that glamor alone could provide the basis for capitalization totaling tens of billions of dollars for an extended period prior to payment of dividends. On the other hand, capitalization of a few billion dollars, combined with firm orders for SPS delivery to utility companies, would provide the leverage necessary for a "Solar Satellite Corporation" to borrow large funds for construction. Such capitalization should be available from a conbination of corporate and individual investors. Figure 11 shows the flows assumed under this model, in which "SOLARSAT" would be chartered by act of Congress to establish a global SPS system.

Once "SOLARSAT" is operating, the formation of an international entity analogous to INTELSAT could follow rapidly. In contrast to the INTELSAT system, however, it is unlikely that most member nations would be willing to have the international organization maintain title to the power satellites but would prefer to buy them outright.

Although INTELSAT has used COMSAT as a manager under contract, it is not permanently committed to do so. Neither is COMSAT thus constrained to use U.S. launch vehicles but may use any available competitive system. The European Space Agency's ARIANE vehicle may prove to be competitive in cost, as may OTRAG's privately developed booster which has had several suborbital test flights from Zaire. Similarly, an international SPS organization such as described here would be free to hire any of its member organizations to act as managers or contractors for construction and maintenance of pirer satellites. 


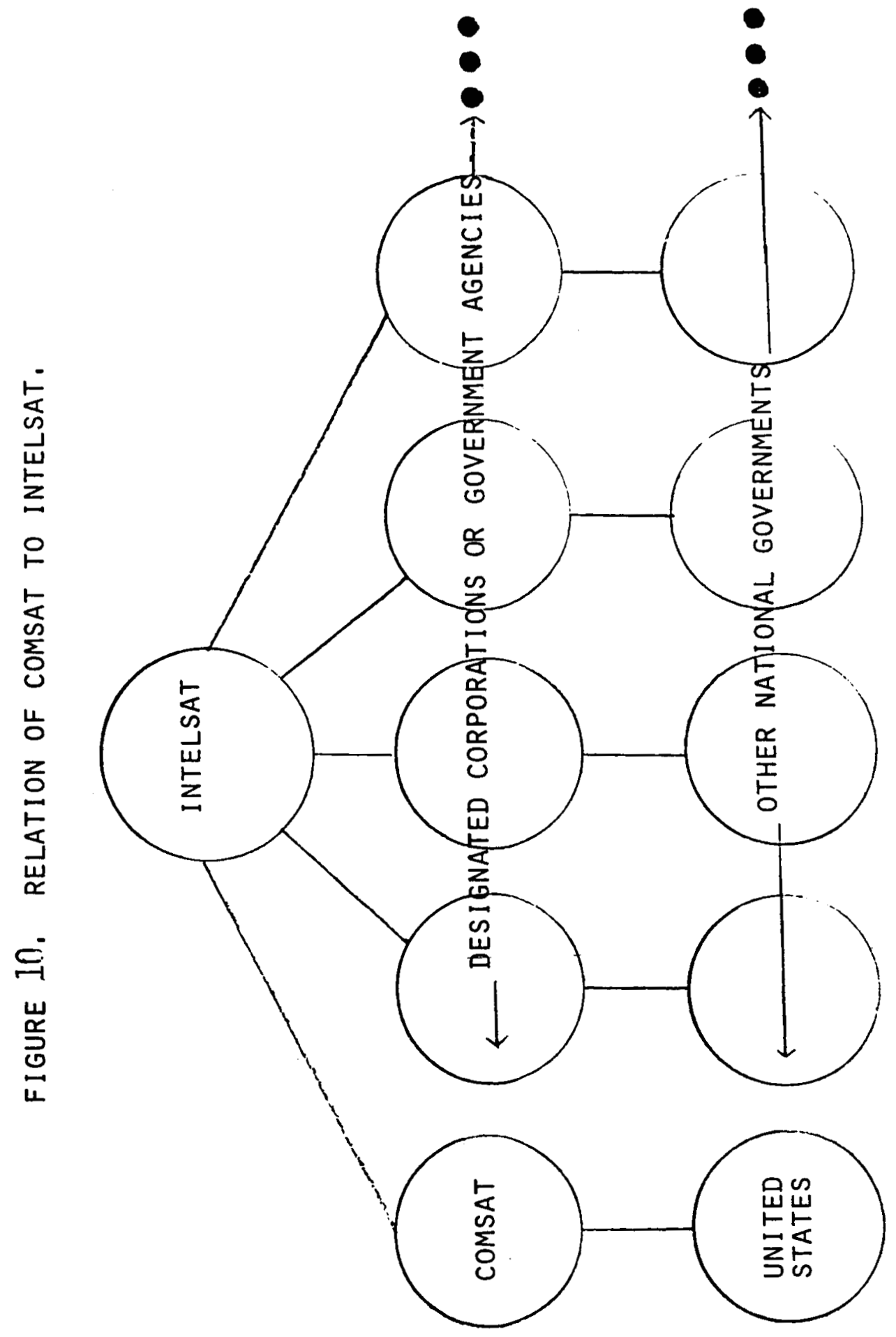




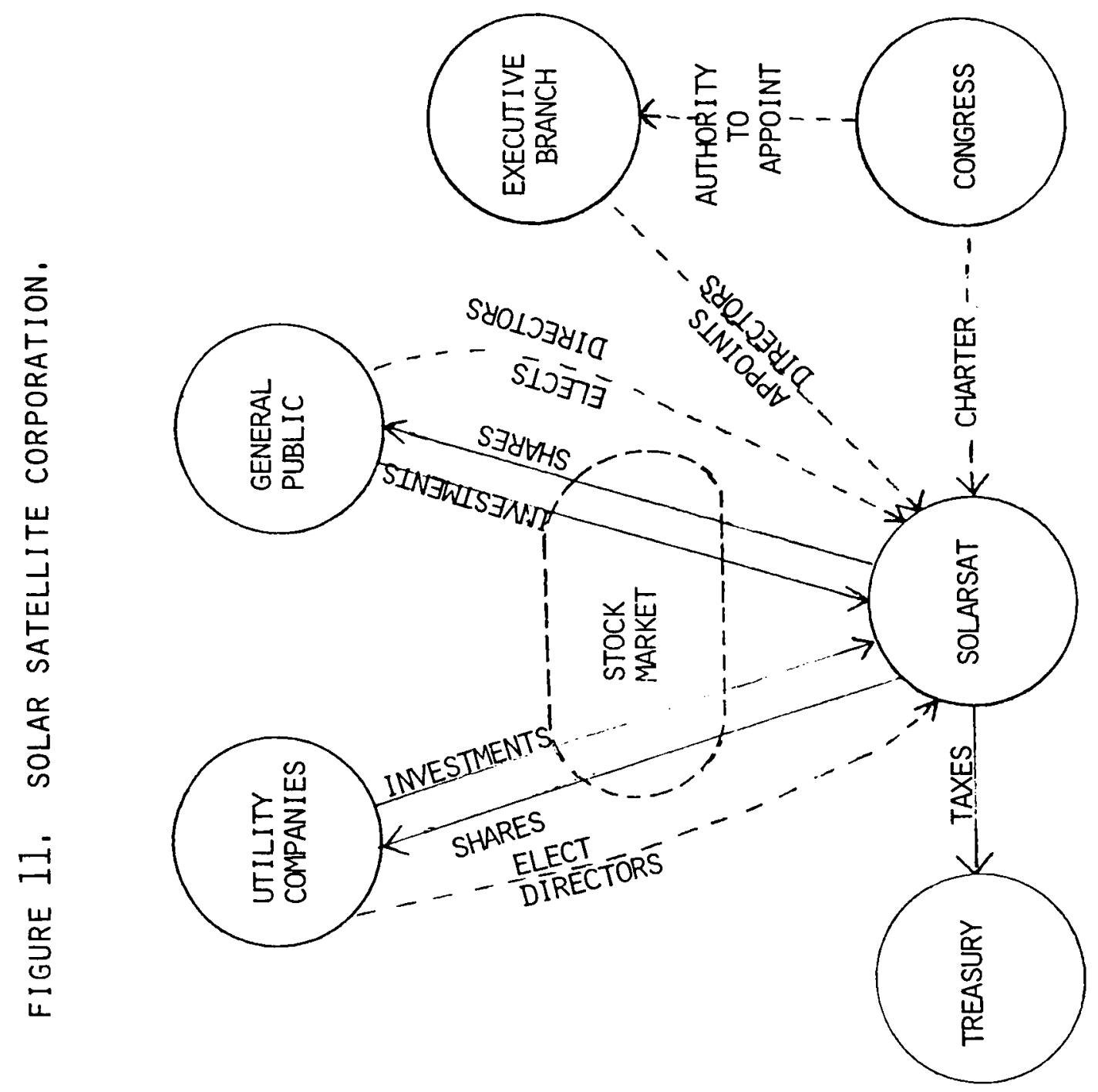


8. The consortium model. Confronted with very large projects of moderate risk, private enterprises have frequently turned to the formation of an ad hoc consortium to distribute the management of the project and the investments required so that none of the partners in the venture is overextended. Some recent projects which have successfully used this method include the Alaska pipeline, the North Sea oll fields, and the construction of some large base-load electrical generating plants.

When the Saudi Arabian government decided to build the new University of Riyad, it solicited bids for the total project from engineering companies around the world. The low bid (for $\$ 3.4$ biliion) was submitted by a consortium formed for this project by Bouyges (Paris, France) and Blount, Inc. (Montgomery, Alabama). Although three other consortia also submitted bids, a fifth combine elected not to bid because the project was still too large for them too manage. Presently, the Saudi government has begun to build an entire new city in northeastern Saudi Arabia to be called King Khalid Military City. The total project will cost more than $\$ 7$ billion, and will be contracted out under some 34 different contracts ranging in cost from \$100- to \$150-million. Construction of the support facilities for these contractors, however, is a single project of about $\$ 1$ billion; this task has been awarded to Morrison-Knudsen Saudi Arabia Consortium, a combine which includes Morrison-Knudsen of Arabia, Inc. (Boise, Idaho); Fischbach and Moore International Corporation (Dallas, Texas); and a Dutch concrete consultant, Interbeton Construction N.V. (Curacao).(11)

While a consortium can break up a large project into smaller pieces which can be managed by existing corporations, this organizational arrangement cannot change the time scale necessary for an acceptable return-on-investment and an acceptable level of profitability. The consortium would thus have to rely on R\&D work previously paid for by others, either a government agency or a staging company. Flows applicable to the consortium model are shown in Figure 12 .

Because of the large scale of an SPS construction program, several distinct consortia may enter the field, providing the classical benefits of competition and avoiding the risks of excessive concentration of power. Utility companies could shop around for the best bargain available to them, just as they presently can buy turbogenerators from Westinghouse or from General Electric or several other manufacturers. Several different consortia may also be able to offer variations in SPS designs and sizes, facilitating integration of power satellites into existing grids. Such an approach would clearly minimize military identification of the SPS program.

Consortium partners would be financed by a combination of stocks, long-term bonds, and advance deposits on utility company orders for power satellites, with little or no government support beyond the initial R\&D support. 


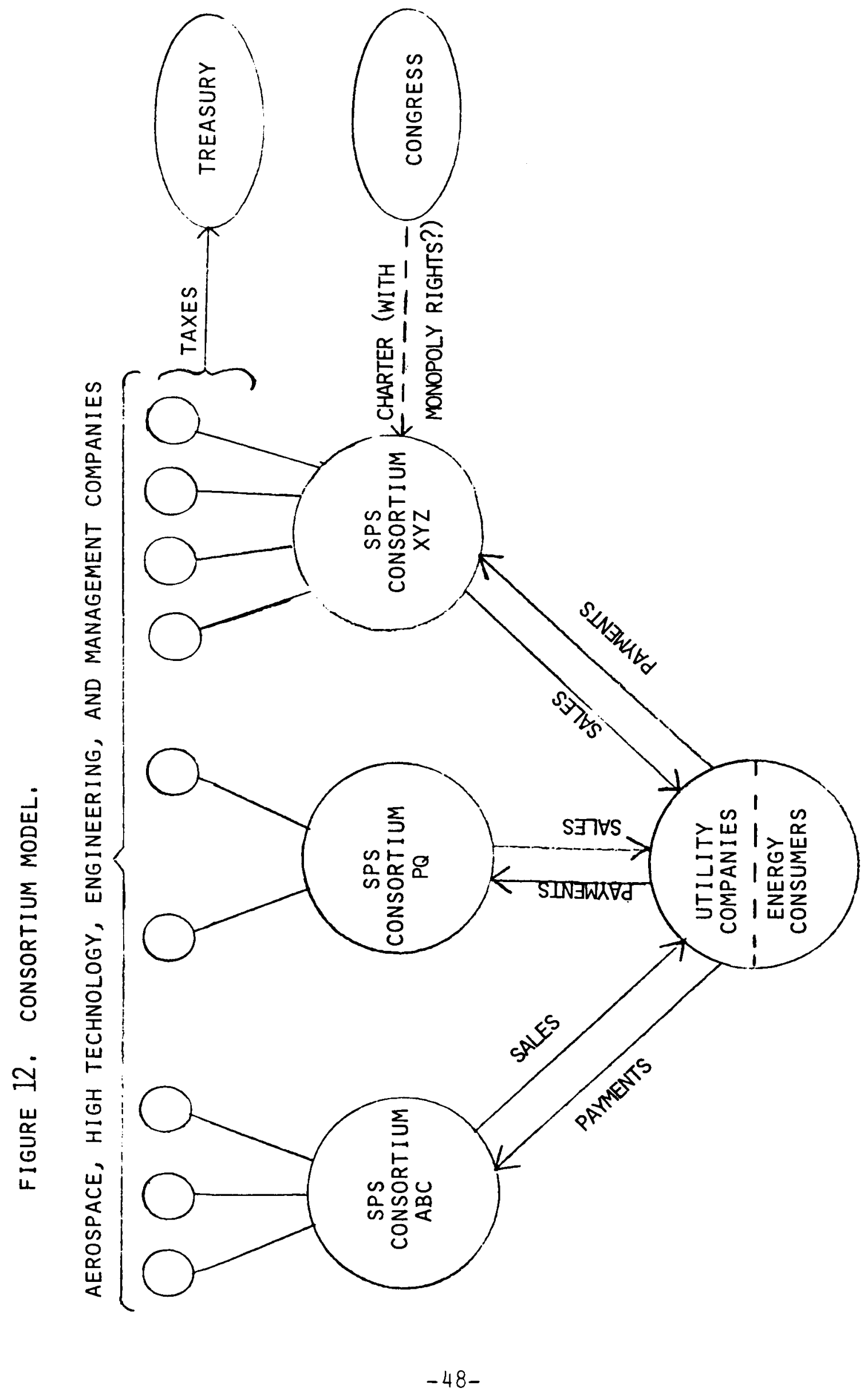


9. The corporate socialism model. Perhaps the earliest application of this idea was the Pacific Railroad Act of 1862 designed for the purpose of creating a transcontinental railroad. The act created the Union Pacific Railroad and authorized the Central Pacific Railroad to participate as well. The basic premise was that if the nation as a whole needed a particular project to be done, the taxpayers should help to pay for it by supporting private enterprise in both of its classic endeavors: getting the job done and making a profit by doing the job.

The Pacific Railroad Act gave the railroads an outright grant of right-of-way through public lands and additional lands for each mile of track completed. The rallroads also recelved payment in the form of 30-year U.S. bonds, principal and interest payable at maturity. Due to insufficient safeguards, the situation was exploited by the infamous Credit Mobilier, but the job was completed by 1869 and all loans advanced to the railroads were completely repaid by 1895 . (12)

Preferential tax treatment has been used in several other countries much more extensively than in the United States. At the end of World War II, Sweden was still an agrarian economy. The government decided to stimulate the development of industry by a combination of incentives favoring private investments in new technologies. Thirty years later, Sweden is a major industrial nation producing some of the most sophisticated military aircraft in the world and earning significant export revenues from sales of automobiles throughout the world. (13) During the last ten or fifteen years, the Republic of Ireland has deliberately encouraged forelgn industry to establish new factories in Ireland by offering exemption from all corporate taxes for up to ten years.

Similar incentives for private industry in such a new and sophisticated technology as SPS could stimulate not only the commercialization phase of an SPS program but part of the R\&D phase as well.

With more sophisticated safeguards, available today, an SPS program could be carried through by private enterprise companies using a combination of equity financing through the public stock and bond markets, government guaranteed loans, government loans, outright government grants and subsidies, preferential tax treatment, and other incentives. In return for this support, the taxpayers would recelve diffuse and indirect benefits including technological spin-offs, stimulation of economic growth, and (eventually) reduced energy costs. The flows involved for the corporate socialism model for SPS are shown in Figure 13.

Advantages of this approach include its historical familiarity and its diffusion of financial, management, and employment participation over a very wide base. Disadvantages may include the difficulty of coordinating such a diversified operation, although the Marshall PIan after World War II used a wide array of private 

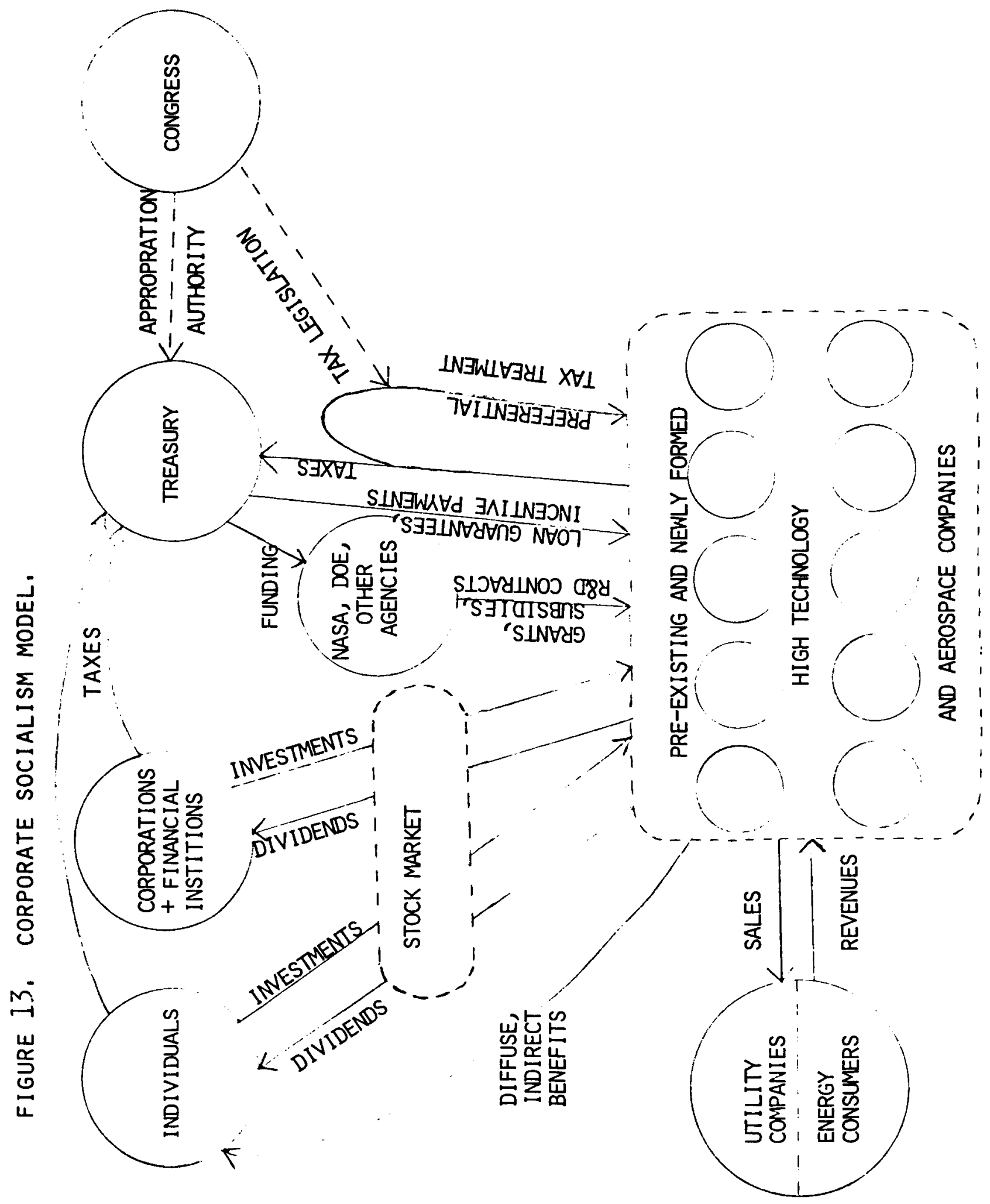
companies and government agencies very successfully. (5) In the present political climate, however, political acceptability of a proposal to pour biliions of dollars a year of the taxpayers' money into a select few aerospace companies would be low. (Consider the Lockheed loan guarantee, which ended up costing the taxpayers nothing, yet created a major battle in Congress because of the magnitude of the potential risk.)

10. The universal capitalism model. In their book How to Turn Eighty Million Workers Into Capitalists on Borrowed Money, Louis 0 . Kelso and Patricia Hetter proposed a fundamental economic reform to improve the performance of the U.S. economy. This plan is based on the theory of universal capitalism (alternatively known as the two-factor theory of economics) developed in the books of Kelso and Mortimer J. Adler, The Capitalist Manifesto and The New Capitalists (9). The basic model is summarized in Appendix II; its specific application to the SPS commercialization program is discussed here.

The basic purpose of Kelso and Hetter's plan is to promote the ownership of capital (principally in the form of shares of stock) by wage earners and by welfare re:ipients throughout society. By setting universal ownership of capital as a national goal instead of (or in addition to) the goal of universal employment, everyone would eventually have a second income from dividends in addition to an income from wages or welfare. If the dividend income became large enough, most welfare payments could eventually be eliminated. To accomplish these goals, Congress would have to fist charter a "Capital Diffusion Insurance Corporation." (Alternatively, existing insurance companies could assume the same role under suitable enabling legislation.) Individuals desiring to participate in the plan would pay a loan insurance premium to CDIC and borrow money from conventional lending institutions to purchase shares. As insurer of these loans, CDIC would maintain a list of approved ventures which CDIC believed were reasonably safe investments. The individual would purchase shares with the loan; the shares would be held as collateral until the loans (including interest) had been repaid out of the dividends of the shares purchased. If the shares became worthless, or if they paid insufficient dividends to pay off the loan, CDIC would bail out the lending institution. In most cases, the dividends would pay off the loans in 5 to 7 the dividends were pald out of pre-tax dollars.

Were such a reform to be Implemented, the commerciailzation phase of the SPS program could be financed similarly. Figure 14 shows the flows of capital and of authority applicable to an SPS organization in this model. This would have many of the same benefits of the taxpayer stock corporation; since it presupposes the willingness of Congress and the Executive to carry through a very large scale economic reform, its political viability would seem to be low. It is not likely that political and ideological biases opposing the underlying ideas here could be overcome purely by the lure of inexpensive electrical power from SPS. On the other hand, it should be borne in mind that very large scale 


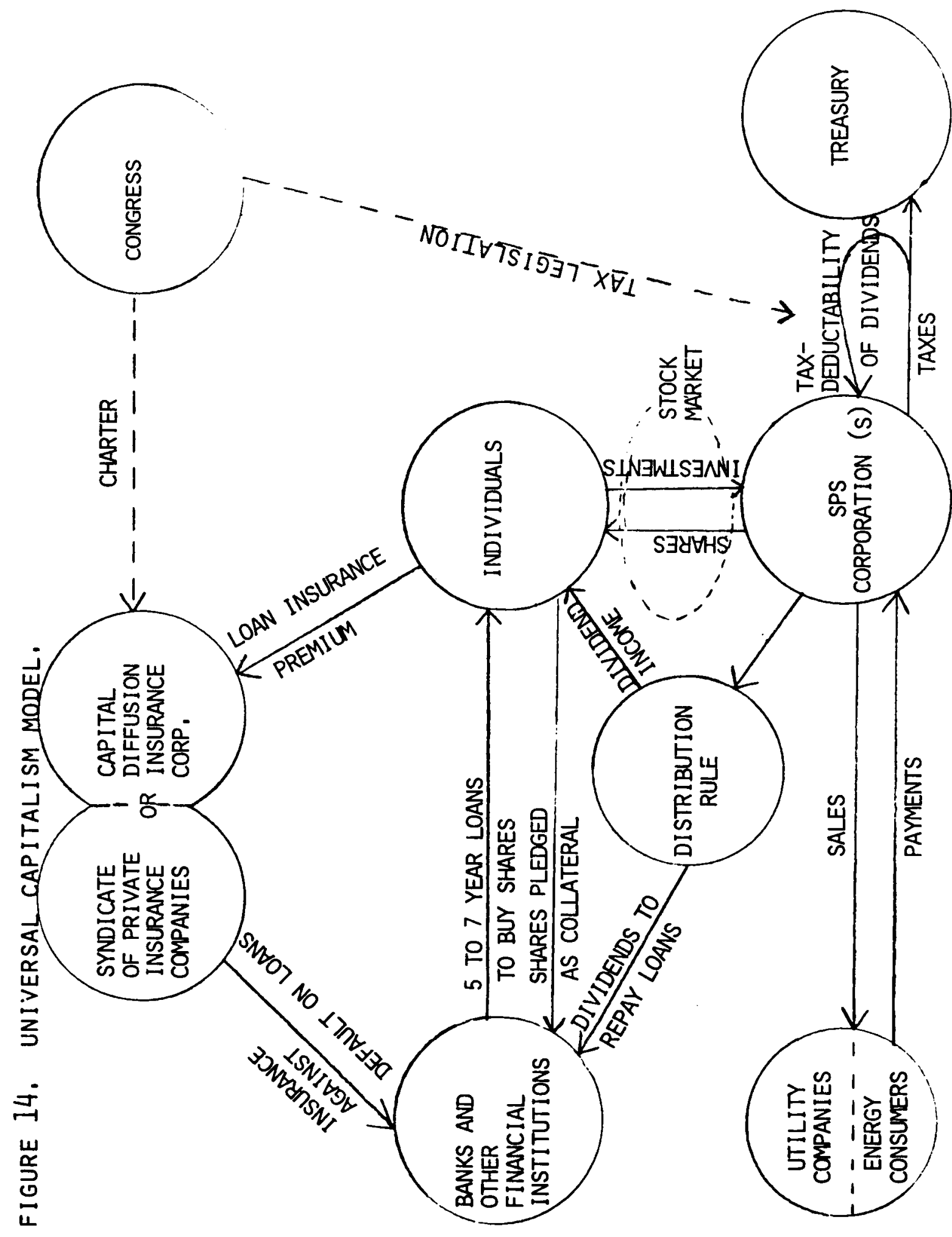


projects in the past have sometimes been carried out for the deliberate purpose of reforming the economic, social, and political structures of a nation. (The construction of the Great Pyramids at Giza seems to have been deliberately geared to uniting the Northern and Southern Kingdoms of Egypt.) Should the ideas of universal capitalism become politically desirable, the SPS program could become the vehicle for this deliberate reorganization of the economy. Some further discussion of the social and economic benefits of universal capitalism can be found in $(14)$.

\section{PHASED APPROACHES}

From the above discussion, it is clear that many different ways of carrying out an SPS program are likely to be workable. It is likely that in actual practice no single form will be used for the entire duration of the program. Even if International Sateliite Industries, Inc., were the only organization which actually sets out to carry out an SPS program, it would make use of R\&D efforts by DOE and NASA in its own programs. Thus the likelihood of phased approaches should be kept in mind in any further consideration of SPS financing and management.

Various hybrid cases may also be worthy of consideration. During the R\&D phase, for example, it may be desirable and advantageous to have existing agencies (such as DOE and NASA) supported by appropriations from general taxation, by very modest, energy user taxes, and by space Bonds, with the bonds redeemable from general tax revenues should no commercial products or services in fact materialize from the R\&D phase.

In view of the length of the R\&D phase which still lies ahead, it is definitely premature at this time to make any decisions concerning the commercialization phase of an SPS program, even if full scale committment is made to the R\&D phase. Most likely no really sound basis for decision on whether to proceed with the full DDT\&E program can be made until a substantial portion of the verification phase has been completed; it would seem to be reasonable for DOE and NASA to pursue such a program within the present framework of annual appropriations from general tax funds.

One drawback to a phased approach in which the R\&D effort is carried out by a different organization from that which will actually build and sell the power satellites is that the R\&D organization would have limited motivation for reducing the costs per kilowatt of the power satellites, and would have strong motivation for prolonging the $R \& D$ phase. Perhaps these problems could be alleviated by using two or more organizations in parallel and in competition. To some extent, this will happen between DOE/NASA and ISI should ISI raise sufficient capitalization to undertake a significant level of R\&D toward SPS. 


\section{COMPARATIVE EVALUATION}

Our preliminary, qualitative, and highly subjective assessment of the ten alternative organizational forms for SPS is summarized in Table II. The summary table shows that the latter five forms (all of them private enterprise) appear mor favorable than do the purely governmental forms, the first five on the list. This preference is in large measure due to the fact that the criteria discussed earlier are strongly tilted toward measurement of the performance of an SPS organization during the commercialization phase, with less weight Eiven to performance during the R\&D phase. Under such circumstances, private enterprise approaches could be expected to be strongly favored in the evaluation.

As far as performance during the R\&D phase is concerned, we have little basis for expecting significant differences among the various governmental forms discussed, except for the following considerations:

(1) An SPS R\&D program might tend to "get lost in the shuffle" in large multi-program organizations such as DOE or NASA.

(2) With charter exemption from Civil Service procedures, a new organization would avoid some of the severe managerial handicaps of most government agencies.

(3) The taxpayer stock company approach has some profit motives to push its R\&D phase toward innovation and breakthrough.

All of the governmental organizations for sPS would have difficulties in achieving a convincing separation from the military, leaving major concern about the possibility of strategic destabilization. In the face of uncertainties in international space law, it is highly doubtful that any of these organizations could act decisively. Bureaucratic inertia may make it very difficult for any of these organizations to move rapidly, retarding the impact of the SPS program on U.S. energy supply. Except for the hybrid forms (such as the taxpayer stock corporation or the bond-financed agency), the governmental forms are likely to be unstable in varying degrees to shifts in Congress and in the Executive.

Perhaps the major uncertainties concerning the various private enterprise approaches are the ability of Third world countries to be active participants (besides being customers) and the ability of such organizations to protect U.S. technological advantages as effectively as governmental organizations might.

A great deal more study is needed on comparisons of these alternatives, especially since some combination of models may actually be used, in series and/or in parallel. Another guestion 


\begin{tabular}{|c|c|c|c|c|c|c|c|c|c|c|}
\hline \multirow[b]{2}{*}{$\begin{array}{l}\text { TABIE II. } \\
\text { COMPARATIVE EVALUATION } \\
\text { OF ALTERNATIVE SPS } \\
\text { ORGANIZATIONAL FORMS } \\
\text { + Positive } \\
\text { O Neutral or weak } \\
\text { - Negative } \\
\text { ? Uncertain }\end{array}$} & \multicolumn{6}{|c|}{ FULL DURATION } & \multicolumn{4}{|c|}{ COMMERCIALIZATION ONLY } \\
\hline & 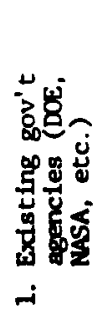 & 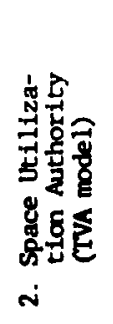 & 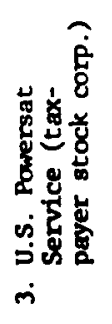 & 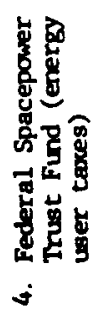 & 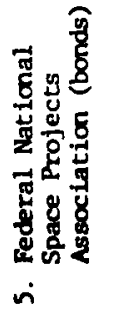 & 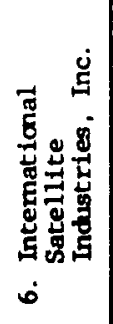 & 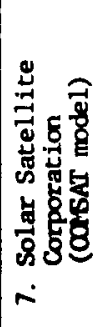 & 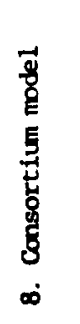 & 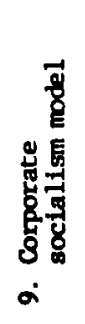 & 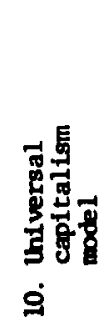 \\
\hline $\begin{array}{l}\text { E-0. Ability to raise the } \\
\text { requisite capital. }\end{array}$ & + & + & + & + & $?$ & $?$ & + & + & + & $?$ \\
\hline $\begin{array}{l}\text { E-1. Appropriate distribution } \\
\text { of risks and benefits. }\end{array}$ & 0 & 0 & + & 0 & + & + & + & + & + & + \\
\hline $\begin{array}{l}\text { E-2. Possibility of wide } \\
\text { participation }\end{array}$ & - & - & + & - & + & + & + & + & 0 & + \\
\hline E-3. Continuity stability, & - & 0 & + & 0 & 0 & + & + & 0 & 0 & + \\
\hline $\begin{array}{l}\text { E-4. Possibility of foreign } \\
\text { sales and participation }\end{array}$ & - & - & 0 & - & 0 & + & + & + & + & + \\
\hline E-5. Maximm inpact on U.S. & $?$ & $?$ & + & $?$ & $?$ & + & + & $?$ & + & + \\
\hline $\begin{array}{l}\text { E-6. Ability to capitalize } \\
\text { an spin-off technologies. }\end{array}$ & $?$ & + & + & + & + & + & + & + & + & + \\
\hline $\begin{array}{l}\text { P-1. Lack of domination by } \\
\text { 'big govermment' }\end{array}$ & - & - & + & - & 0 & + & + & + & 0 & + \\
\hline $\begin{array}{l}\text { P-2. Protection of U.S. tech- } \\
\text { nological advant ages }\end{array}$ & + & + & + & + & + & $?$ & ? & $?$ & + & $?$ \\
\hline $\begin{array}{l}\text { P-3. Opportunity for Third } \\
\text { World participation }\end{array}$ & - & - & $?$ & - & $?$ & $?$ & $?$ & $?$ & $?$ & $?$ \\
\hline M-1. Minimm identification & - & 0 & 0 & 0 & 0 & + & + & + & 0 & + \\
\hline $\begin{array}{l}\text { M-2. Assurance against } \\
\text { strategic destabilization }\end{array}$ & - & $?$ & $?$ & $?$ & $?$ & + & + & + & $?$ & + \\
\hline S-1. Widespread participation & - & 0 & 0 & 0 & 0 & + & + & + & + & + \\
\hline $\begin{array}{l}\text { S-2. Flexibility with respect } \\
\text { to divestiture, liquidation }\end{array}$ & - & - & + & - & - & + & + & + & + & + \\
\hline $\begin{array}{l}\text { S-3. Ability to act decisively } \\
\text { in framework of space law }\end{array}$ & $?$ & $?$ & $?$ & $?$ & $?$ & + & $?$ & + & $?$ & + \\
\hline $\begin{array}{l}\text { T-1. Ability to foster, utilize, } \\
\text { disseninate imovations }\end{array}$ & $?$ & 0 & + & 0 & 0 & + & + & + & $?$ & + \\
\hline $\begin{array}{l}\mathrm{T}-2 \text {. Ability to stimulate } \\
\text { continual upgrading of SPS }\end{array}$ & $?$ & 0 & + & 0 & 0 & \pm & \pm & \pm & $\stackrel{?}{?}$ & \pm \\
\hline
\end{tabular}




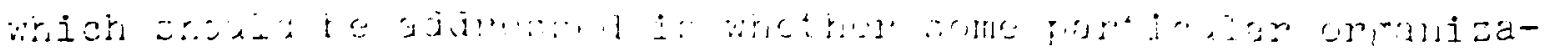

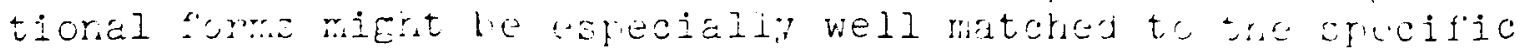

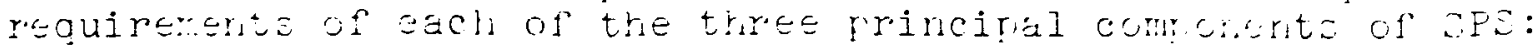

(1) satelite construction and minterar.os;

(2) transportatior and space facilitiez; ara

(3) Eround station construction and mairtenance.

$\mathbb{Z}$ : sersitivity of the various oreanizational forms to charises in the Eeneral socioecoromic context is very important as well. Each. form should be corsidered ir relation to a number of alternative future scenarios besides the surtrise-free future assumed by the Reference Design frojections of costs, electrical demand, ana technology growth. icme of the alternative scerarios wich srould be considered vould include:

(1) Definitive Flans by the Soviet Urion to undertake a laret-scale SPS proenam.

(2) A rapid climatic change toward sienificantly colder and longer winters in the iorthern Hemisphere, with major food and erergy shortages requiring massive intervention neasures, perhaps including a program for deliberate weather and climate modification.

(3) Extensive private entrepreneurial activities in space in the areas of materials processing, irformation services (including personal communications systems, direct television broadcost from orbit, package locator services, geological prospecting, and commercial reconnaissance services, and space-tourisn with second-generation reusable. vehicles.

(4) Extensive military operations in space by the Unite: States, by the Soviet Union, and/or by other natiors or groups of nations.

The time and resources available for this study did not permit us to pursue such an evaluation of oreanizational candidat $E \equiv$ against alternate futures, although this is an important consideration winich should be followed up in further studies.

\section{KEY ISSUES AND OBSERVATIONS}

Diring the Sixteenth Certury, when the New Vicrld and the Far East vere first being exrioited by the maior European powers, Spain, England, and the Netherlands invested up to about $1 \%$ of their respective GNP's in colonization projects. For England and the Netherlands, which had far less centralizatior of power than cid Spain, this :as only possible because of a rev social invent1c: for firancing large and expensive undertakings. Trat new social invention was the joint stock company. 


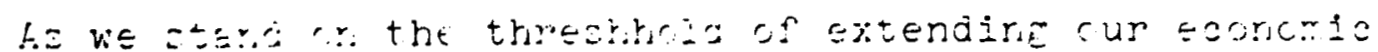
syster. 1rte er. ther now world, vis soo mey reed a rew socidi invention fcr mikirig possible lares-scale projects approaching 1\% of our G!:F over an extended period. (The ADollo Frogram at its peak involyed $\frac{1}{2} \%$ of GNP for two or three years.) Three of the orgarizational forms mentioned above are completely new social inventions: the taxpayer-stock corporation, the staging company, and the universal capitalism model. The concept of using long-term. bonds to finance a long-term $R \& D$ project which is reasonably likely to provide large profits is a new twist on an old iaea. These four organizational ideas, in particular, deserve a good deal more study to examine their ramifications throughout soclety.

The entire question of whether private industry or government should carry out an SPS procram (or, indeed, any largescale program) inevitably has a strong ideological component. To the extert possible, the advartages and disadvantages of each position need to be spelled out in great detall by advocates of each position. (15) The ultimate decision probably must be made in the marketplace and in the polling booths. The formation of International Sateliite Industries, Inc., may prove to be catalytic in the entire field of space utilization during the next few decades. ISI presently hopes to make its first public offering of common stock about the beginning of 1979. To the extent necessary and possible, legal and administrative steps should be taker to clear the way for ISI to give this experiment a reasonable chance to prove itself.

Federal participation in the R\&D phase would probably be most successful if it were at least partly funded by longterm "Space Bonds." The sale of U.S. bonds to help win the war was highly successful because it gave people a sense of participation in a clearly defined, large-scale goal consis sent with the personal values of most of the population. Human expansion into space seems to be highly consistent with traditional American values; personal participation during the R\&D phase is likely to be successful, provided the effective interest were competitive. Exempting interest on space Bonds from federal taxes would help stimulate widespread participation, especially if they could be traded commercially in modest lots. The eventual redemption of the bonds could be based on a licensing fee for each power satelite manufactured by a U.S. corporation or sold to a utility company in the U.S.

Internationaliy, it seems that the INTELSAT model may be the most viable system, with each participating country free to specify what type of domestic oreanization may represent its interests. Representation in such an international organization need not, perhaps, be limited to a single entity per country, particularly if voting rights are based on share of the capitalization of the international body.

Recognition of the divisibility of the SPS program into an R\&D phase and $\equiv$ commercial irr-ementation phase is key to discussions of furding and management schemes. 


\section{RECOMMENDATIONS FOR FURTHER STUDY}

\section{NEAR TERM STUDIES}

1. The Existing Baseline and Reference Designs for SPS are based on relatively simple ereineering optimization choices on the basis of which a fairly detailed design has been developed and costed. Commercial viability of SPS, however, will require a different design philosophy: design to cost. To determine a viable commercial cost, a benefit/cost analysis should be done to determine the necessary margin between a low-cost SPS and fossil fuel or nuclear generating plants after 1990 which would justify the expenditure of tens of billions of dollars for the R\&D phase. Variables which should be considered include future price trends for petroleum, coal, natural gas, and fissionable materials; trie costs and schedule for the SPS R\&D effort; and the potential for decrease in the costs of SPS.

2. In view of the large number of design alternatives for a Satellite Power System, and the large uncertainties associated with many of the cost components for each of these alternatives, the development of a parametrized cost model for a general SPS model is now essential. Such a model would provide the guidance needed to optimize the costs of the system, suggesting which components of cost offer the greatest prospects for decreasing total system cost. In addition, such a model would be a valuable tool in a design-to-cost approach.

3. A detailed financial analysis should be made of each of the possible organizational forms discussed in this paper, with consideration of the costs of abandoning the project before completion.

4. A detailed study of the legal and regulatory aspects of each of the organizational forms discussed in this paper should be carried out, defining legal obstacles and potential solutions for each obstacle identified.

5. The viability of each organizational form and the sensitivity of its financing to variations in total demand for SPS power, total investment capital available, cost per kilowatt, for SPS, and timescales for the R\&D and the commercialization phases of the SPS program should be examined in the contexts of several alternative scenarios for the future. Among the scenarios examined should be the following possibilities:

(a) Major Soviet SPS program;

(b) Rapid and major climatic change in the Northern Hemisphere, moving toward an ice age;

(c) Extensive private enterprise in other types of space industries;

(d) Extensive military operations in space by two or more nations. 
6. Tre cccomic advantages of usine equatcoial laurch sites versus laurch sites within the territory of the ljnited States should be actermined, both srecificaliy and as part of the carametrized cost model recommerided above. Should the bsnefits outivigh the fully amortized costs of constructing a rew launch complex or the costs of using a laurici site provided by some independent Erolip such as Earthport (i6), the relative advantages of a private enterprise approach to commercial implementation versus a governmental approach may be altered significartly. The questions of Third World participation and of protection of U.S. tecinnological advantages must be considered carefully in the context of a launch site on foreigr soil or afloat in internationa: waters. National security implications of deploying systems with advanced technology abroad must also be considered.

7. For a system as complex as the SPS program, an organization carrying out a lengthy R\&D effort and/or implementation program will require far more effective and complete irternal access to detailed information concerning the entire system. Some effort should be given to conceptual designs for computerization of management tools such as PERT charts and CPM charts for the entire project, in a form accessible to workers throughout the organization. Similar systems for engineering design information should also be considered. These systems would facilitate innovative ideas from unexpected quarters which could then be channeled rapidly to the appropriate section of the overall organization for consideration.

\section{LONGER TERM STUDIES}

1. Throughout most of the Third World, the major demand for energy is for cooking and space heating. The worldwide market for SPS would thus be significantly expanded if SPS electricity could be used as a primary energy source for the synthesis of liquid fuels (such as methanol) and for the synthesis of fertilizers (such as ammonia). Similarly, in the United States and other industrialized countries, electrical demand is a small portion of total energy demand. The market for SPS would be expanded if SPS electricity could be used for the electrolysis of water to provide the basis of a hydrogen economy. Thus preliminary designs and costing should be done for SPS interfaces with a hydrogen economy and with the synthesis of liquid fuels. A slight decrease in SPS costs below the Reference Design would make liquid fuel synthesis from SPS power cheaper than present energy sources in much of the Third World. To make an SPS-based hydrogen economy feasible in industrialized nations, SPS costs would have to be substantially reduced from the ievels of the Reference Jesign.

2. Freliminary enEineering studies should begin soon to examine altemaifue desibli curuelits and conriguratiors. sheuld the cost per kilouatt fall sicnificantly below about $\$ 1000$, SPS 
ajij socoms a sar more significart contritution to j.:. electrica:

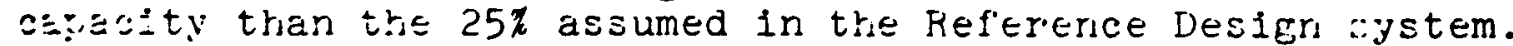
$\because$ incit sucr studies to provide adaitional design poirits in the rérar:etrized cost model recommended above, we will have little reascnable basis for selecting the optimum SPS candidate. In corisidering an SPS program extending fifty years into the future, tr.e use of ronterrestrial materials in SPS construction, in particular, cannot be ignored resporisibly. 


\section{REFERENCES}

1. "Solar Power Satellite Baseline Review," MSFC and JSC, IIASA Headquarters, July 13, 1978.

J. Hamaker, private communication, August 8, 1978.

2. Space Industrialization 1980--2010, Sclence Applications, Inc., Final Report, NASA Contract NAS 8-32197, April 1978.

3. Richard A. Falk, A Study of Future Worlds, D. 59, NacMillan Publishing Company, Inc., New York, 1975.

4. J. Henry Glazer, "Juridical Models for Space Settlements," Earth/Space News, No. 5, p. 9, July 1976.

5. James E. Webb, Space Age Management: The Large Scale Approach, McGraw-Hill Book Company, New York, 1969.

Feter F. Drucker, The Effective Executive, Harper and Row, Publishers, Inc., New York, 1966, 1967.

6. Philomena G. Grodzka, "A Space Utilization Authority (SUA) Could Be the TVA of the Future," paper presented at southeast 2001: The Next 25 Years, November 12-13, 1976, Urban Life Center of Georgia State University, Atlanta, Ga., sponsored by the World Future Society.

Philomena G. Grodzka and James A. Tevepaugh, "Expanding NASA's Charter to Facilitate Space Utilization," pp. 627645 in R.A. Van Patten et al, eds., The Industrialization of Space, Vol. 36, Advances in the Astronautical Sciences, American Astronautical Society, San Diego, 1978.

7. George E. Fredericks and Richard D. Stutzke, "Space Colonization: Its Inevitability and Its Financing," copyrighted r.imeo, 1977, available from R.D. Stutzke at Science Applications, Inc., 2860 South Circle Drive--Suite 2224, Colorado Springs, Colorado 80906.

8. Christian 0. Basler, "Space Industrialization, the Challenge to Private Enterprise Capitalism," pp. 1063--1079 in R.A. Van Patten et al, eds., The Industrialization of Space, Vo. 36, Advances in the Astronautical Sciences, American Astronautical Society, San Diego, 1978.

Christian 0. Basler, "Preliminary Prospectus: International Satellite Industries, Inc.," private commlinication, June 1978. 
9. Louis C. Yelso and Patricia Hetter, How to Turn Eighty Milzion Workers Into Capitalists on Borrowed Money, Random House, New York, 1967.

10. Commurications Satellite Corporation, "Prospectus: 10,000,000 Shares, Communications Satellite Corporation Common Stock," June 2, 1964.

11. Anonymous, "Saudis cast \$7-billion city on empty desert site," Engineering News-Record: MeGraw-Hili's Construction Weekly, p. 24, July 13, 1978.

12. Oliver Jensen, The American Heritage History of Railroads in America, American Heritage Publishing Co., New York, 1975.

Agnes C. Laut, The Romance of the Rails, Tudor, New York, 1936.

L.R. Mayer and K.E. Vose, Makin' Tracks, Praeger Publishers, New York, 1975.

Bernard A. Weisberger et al, The LIFE History of the United States, Vol. 7: The Age of Steel and Steam, Time Incorporated, New York, 1964.

Charles A. Beard and Mary R. Beard, A Basic History of the United States, Doubleday, New York, 1944.

13. Peter F. Drucker, The Age of Discontinuity: Guidelines to our Changing Society, Harper and Row, Publishers, Inc., New York, 1968, 1969.

14. J. Deter Vajk, Doomsday Has Been Cancelzed, Chapter 34, Peace Press, Culver City, California, Fall 1978.

15. See, for example, Robert W. Poole, Jr., "Hidden Perils in Goverrment Support of Space Activities," pp. 611-625 in R.A. Van Patten et al, ed., The Industrialiaation of Space, Vol. 36, Advances in the Astronautical Sciences, American Astronautical Society, San Diego, 1978.

16. Mark Frazier, "Frontiers for Free Trade," pp. 885-898 in R. ... Van Patten et al, eds., The Industrialization of space, Voi. 3E, Advances in the Astronautical Sciences, American Astronautical Society, San Diego, 1978.

The Satre Foundation, 221 west Cavillo Street, Santa Barbara, Califcrnia 93101 , publishes a newsletter, Earthport Bulzetin, descrining progress on its Earthport Project to establish an interrational commercial launch site on the equator. 